\title{
Planificación de las áreas de transporte de mercancías en la Comunidad Autónoma de Andalucía
}

\author{
Ana Isabel de la Torre López \\ Letrada de la Dirección de Áreas Logísticas y Transportes \\ Agencia Pública de Puertos de Andalucía
}

SUMARIO: I. INTRODUCCIÓN. I.1.La intermodalidad en el transporte de mercancías. 1.2.La logística. 1.2.1.Red de áreas logísticas de Andalucía. I.2.2.Las Plataformas Logísticas.- II. ÁREAS DE TRANSPORTE DE MERCANCÍAS. II.1.CONCEPTO DE ÁREAS DE TRANSPORTE DE MERCANCÍAS. II.2.Clases: Centros y estaciones de transporte de mercancías. II .2.1.Centros de transporte de mercancías. II.2.2. Estaciones de transporte de mercancías.- III. ADMINISTRACIÓN COMPETENTE. PROMOCIÓN Y ESTABLECIMIENTO DE LAS ÁREAS DE TRANSPORTE DE MERCANCÍAS. III.1. Estatuto de Autonomía para Andalucía. III.2. La Ley 5/ 2001 reguladora de las áreas de transportes de mercancías en la Comunidad Autónoma Andaluza. III.3. Gestión del suelo de las áreas de transporte de mercancías. III.4. Titularidad, dirección y gestión de las áreas de transportes de mercancías.- IV. PLANIFICACIÓN TERRITORIAL: LEY 1/ 1994, DE 11 DE ENERO DE ORDENACIÓN DEL TERRITORIO DE ANDALUCÍA. IV.1.Instrumentos de planificación territorial. IV.2.Actuaciones de interés autonómico. Efectos. VI.3.Incidencia de las áreas de transporte de mercancías en la ordenación del territorio y medio ambiente.- V. PLANIFICACIÓ N U RBANÍSTICA. V.1. Instrumentos de planificación urbanística. V.2. Supramunicipalidad, declaración de interés autonómico:efectos.- VI. PLANIFICACIÓN FUNCIONAL. VI.1 Plan Funcional: Concepto y contenido. VI.2.Plan Funcional como proyecto de actuación. VI.3.Efectos del Plan Funcional sobre la planificación urbanística.- VII. CENTROS DE MERCANCÍAS EXISTENTES Y PROYECTOS EN DESARROLLO.- VIII. CONCLUSIONES: VALORACIÓN DEL RÉGIMEN NORMATIVO EXISTENTE EN LA MATERIA: Ley 5/ 2001

\section{INTRODUCCIÓN}

Las áreas de transporte de mercancías de la Comunidad Autónoma Andaluza aparecen reguladas en la Ley 5/ 2001 de 4 de junio, de acuerdo con las 
competencias atribuidas, dentro del marco establecido por la Constitución Española de 1978, por el Estatuto de Autonomía de Andalucía aprobado mediante Ley Orgánica 6/ 1981 de 30 de diciembre, hoy derogado en virtud de la Ley Orgánica 2/ 2007 de 19 de marzo de reforma de dicho Estatuto.

La promulgación de la citada ley supuso, además, la superación del marco normativo existente en la materia integrado por la Ley estatal 16/ 1987, de 30 de julio de Ordenación de los Transportes Terrestres, y su Reglamento aprobado por Real Decreto 1211/ 1990, de 28 de septiembre que únicamente regulan las denominadas «estaciones de transporte de mercancías» dentro de las «actividades complementarias o auxiliares del transporte», sin referencia alguna a las áreas o centros de transporte de mercancías, desde una perspectiva puramente local, sin atender a aspectos relativos a la planificación territorial o urbanística.

La promoción de las áreas de transporte de mercancías en la Comunidad Autónoma Andaluza y su importancia en el desarrollo de las infraestructuras y plataformas logísticas, hicieron necesaria la promulgación de una ley específica sobre la materia que regulara tales áreas de forma integrada, atendiendo a aquellos aspectos relativos a la planificación territorial y urbanística que, por ser competencia autonómica, excedían de las atribuciones del legislador estatal.

Entre los objetivos perseguidos por la Ley se pueden destacar, principalmente, los siguientes:

- Dotar a las infraestructuras del transporte de un marco regulador propio.

- Integrar la planificación sectorial, territorial y urbanística.

- Mejorar la eficiencia del sistema de transporte andaluz y permitir su articulación con la red nacional e internacional de infraestructuras del transporte y de plataformas logísticas nodales.

- Favorecer la intermodalidad y, con ello, mejorar la productividad del sector.

- Dar respuesta al problema relativo a la ubicación de los suelos destinados a estas áreas, para evitar la expulsión de los usos logísticos por el mercado inmobiliario.

En este sentido, la Exposición de Motivos de la Ley 5/ 2001 dispone que las áreas de transporte de mercancías " $\mathrm{H}$ an de facilitar y potenciar la intermodalidad del sistema y adecuarse a las exigen cias planteadas actualmen te por la demanda de 
tran sporte de mercancías, la cual ya no se identifica, como tradicionalmente, con el me ro desplazamien to físico de la mercancía, sino que in cluye, cada vez más, actividades como las de almacenamiento, gestión de stocks, distribución, marketing, imagen corporativa y, últimamente, actividades que aumentan el valor añadido del producto: embalaje, envasado, control de calidad y otras."

Como se verá más adelante, la ley distingue, dentro del concepto de áreas de transportes de mercancías, entre los centros y las estaciones de transporte en función del mayor grado de complejidad de los primeros y del mayor nivel de participación en los mismos de la Administración y de las empresas del sector del transporte.

Tal y como ha quedado expuesto, la ley incide sobre dos conceptos que considera esenciales a la hora de regular las áreas de transporte de mercancías y que no son sino el resultado lógico de la evolución del sector: la intermodalidad y la logística. Examinemos en primer lugar cada uno de estos conceptos.

\section{I.1. La intermodalidad en el transporte de mercancías}

La expresión transporte intermodal de mercancías, hace referencia a la utilización de cadenas de transporte combinado en las que se emplean dos o más modos de transporte distintos para transportar mercancías de su punto de origen hasta su destino, ya sea por vía terrestre, ferroviaria, fluvial, marítima 0 aérea.

Esta forma de transporte ha recibido tradicionalmente diversas denominaciones tales como polimodal, combinado, intermodal o sucesivo que han sido utilizados por la doctrina de forma indistinta. ${ }^{1}$

Por su parte, el Derecho Comunitario y más concretamente la Decisión del Consejo de la Comunidad Europea núm. 93/ 628, de 29 de octubre, utiliza la expresión "Transporte combinado" para designar al transporte que emplea los modos ferrocarril y carretera, nombre que también es de aplicación al transporte fluvial y marítimo de cabotaje entre países periféricos y los terri-

${ }^{1}$ Si la expresión intermodal es frecuente en la doctrina anglosajona, las de combinado y polimodal son propios de los países francófonos e hispanoamericanos, respectivamente. El término multimodal se generalizó a partir del Convenio de Naciones U nidas sobre transporte Multimodal de Mercancías de 24 de mayo de 1980. 
torios insulares como consecuencia de la inclusión de estos modos dentro de la Red Transeuropea de Transporte. ${ }^{2}$

En los últimos años, el sistema de transporte intermodal de mercancías, por emplear el término utilizado en la Ley 5/ 2001, ha experimentado un crecimiento extraordinario, lo que ha repercutido, a su vez, en el desarrollo del sistema de infraestructuras tanto estatal como regional.

Este desarrollo ha supuesto el establecimiento de grandes centros o terminales de transporte situados en el interior del territorio y unidos vía aérea, ferroviaria o terrestre con los grandes puertos marítimos.

Esto ha sido posible gracias a la innovación y el desarrollo técnico que han permitido incrementar el rendimiento de modos de transporte que hasta ahora se consideraban ineficientes, colocándolos en una situación de competitividad respecto de otros modos de transporte ya consolidados, permitiendo la utilización del modo que resulte más eficaz en cada caso: es lo que se conoce con el nombre de comodalidad.

\section{I.2. La logística}

El desarrollo experimentado por el sistema de transporte en la Comunidad Autónoma de Andalucía tiene una gran trascendencia desde el punto de vista económico, social e incluso medioambiental, por lo siguiente:

- En primer lugar, por la necesidad de disponer de infraestructuras nodales para la gestión eficiente de la intermodalidad y de las infraestructuras de transporte.

- En segundo lugar, porque en una sociedad globalizada en la que la capacidad de interrelación y la accesibilidad son requisitos básicos para la competitividad, el transporte de bienes y personas es clave para el desarrollo económico y la satiffacción de los derechos sociales.

2 Decisión n 1692/ 96/ CE del Parlamento Europeo y del Consejo de 23 de julio de 1996, sobre las orientaciones comunitarias para el desarrollo de la red transeuropea de transporte, que tiene por objeto establecer las orientaciones en cuanto a los objetivos, prioridades y grandes líneas de acción previstas en el ámbito de la red transeuropea de transporte, que van a determinar proyectos de interés común cuya ejecución debe contribuir al desarrollo de dicha red a escala comunitaria. 
- La tercera razón es que el sector del transporte es el que más energía primaria consume procedente de fuentes no renovables y cuyo suministro implica una fuerte dependencia externa.

- Asimismo, porque el transporte es uno de los principales focos de emisión de contaminantes y gases, afectando negativamente a la salud y la calidad de vida de la población.

- Finalmente, porque el flujo del tráfico y las infraestructuras del transporte son grandes consumidoras y segmentadoras del espacio, generando asimismo otros impactos como el ruido y los accidentes, inmisiones cuyos efectos negativos se concentran, fundamentalmente, en el medio urbano donde reside la mayor parte de la población.

El sistema de transporte es único en la medida en la que desde que un producto o materia prima sale de su lugar de origen para llegar al lugar de destino, se han de utilizar los modos de transporte que en cada caso resulten más eficientes. Es lo que se podría denominar como principio de eficiencia en el transporte de mercancías.

En este contexto, se entiende por logística el proceso relativo a la planificación, implementación y control eficiente del flujo de materias primas, productos en curso y productos terminados, así como la información relacionada con ellos, desde el punto de origen hasta el punto de consumo, con el propósito de satisfacer los requerimientos del mercado.

De acuerdo con lo anterior, la actividad logística comprende un conjunto de operaciones que se pueden clasificar en operaciones de gestión, físicas y de tratamiento de la información:

a) O peraciones de gestión: son aquellas que tienen por objeto la planificación física de la logística, como la organización de rutas; organización y control de la cantidad y de la calidad de los productos; gestión de stocks; trámites aduaneros y gestiones económicas.

b) O peraciones físicas: se refieren a la carga y descarga de mercancías así como al transporte de las mismas, que podrá ser unimodal o multimodal, de corta o larga distancia; fraccionamiento o consolidación de las mercancías; preparación de pedidos; almacenaje; clasificación, pesaje y ubicación de las mercancías y actividades complementarias de etiquetaje, embalaje y montaje.

c) Operaciones relativas al tratamiento de la información entre remitentes, destinatarios y operadores. 


\subsubsection{Red de áreas logísticas de Andalucía}

En el ámbito autonómico, el Plan Director de Infraestructuras de Andalucía 1997-2007, contribuyó de un modo decisivo al desarrollo de la red de áreas logísticas de Andalucía en el entorno de los grandes puertos de interés general, con la puesta en marcha de actuaciones tan destacadas como la de la ZAL del Campo de Gibraltar o Las Aletas en la Bahía de Cádiz sobre las que se volverá más adelante.

Posteriormente, el Plan de Infraestructuras para la Sostenibilidad del Transporte en Andalucía 2007-2013 (PISTA 2007-2013) prevé la creación de un Sistema de Áreas Logísticas que funcione como una red para el conjunto del territorio andaluz, de acuerdo con los principios de especialidad, complementariedad y coordinación entre todas las áreas, en las que está prevista la participación de todas las administraciones y agentes del sector.

EI PISTA, parte del marco legal fijado por las siguientes normas:

- Ley 21/ 2007, de 18 de diciembre, de Régimen Jurídico y Económico de los Puertos de Andalucía.

- Ley 9/2006, de 26 de diciembre, de Servicios Ferroviarios de Andalucía.

- Ley 2/ 2003, de 12 de mayo, de O rdenación de Transportes U rbanos y Metropolitanos de Viajeros de Andalucía.

- Ley 8/ 2001 de 12 de julio de Carreteras de Andalucía.

- Ley 5/2001, de 4 de junio reguladora de las áreas de transportes de mercancías de la Comunidad Autónoma de Andalucía.

- Ley 1/ 1994, de 11 de enero de Ordenación del Territorio de Andalucía.

Del mismo modo, este plan debe insertarse en el contexto regional de la planificación territorial y económica, y en el marco estatal y europeo de las estrategias y programación sobre el sistema del transporte, del que son referentes los siguientes documentos:

- El Plan de Ordenación del Territorio de Andalucía (POTA): Realiza la planificación estratégica de las infraestructuras del transporte, definiendo así el modelo territorial de la Comunidad.

- La Estrategia para la Competitividad de Andalucía 2007-2013: Establece las directrices de la política económica andaluza en los próximos años y en él tiene el PISTA su principal referente económico y financiero. 
- El programa operativo FEDER de Andalucía 2007-2013: Documento de programación que permitirá desarrollar en Andalucía las políticas económicas establecidas por la Unión Europea para las regiones Convergencia de la Política de Cohesión, asegurando con ello una fuente de financiación especialmente importante para la ejecución de infraestructuras del transporte.

- El Plan Estratégico de Infraestructuras y Transporte 2005-2020 (PEIT): De ámbito estatal, propone un sistema coherente de infraestructuras y servicios de transporte que incluye desde la planificación estratégica hasta la sectorial, marcando una serie de objetivos funcionales, económico, sociales, medioambientales y territoriales.

- La Política Comunitaria sobre el Transporte. El libro Blanco y su revisión de 2006. ${ }^{3}$

La red de áreas logísticas prevista en el PISTA se apoya en la existencia de un sistema viario y ferroviario de gran capacidad que conecte los nodos, en especial los portuarios, con los grandes corredores de transporte tanto nacionales como internacionales, lo que requiere, a su vez, la conexión eficiente, en el interior de cada nodo, de las grandes infraestructuras modales: puertos, terminales ferroviarias de mercancías, áreas de transporte de mercancías y, en su caso, aeropuertos.

El conjunto de nodos logísticos que componen dicha red operan en un ámbito supramunicipal y se clasifican en los siguientes:

- Nodos litorales: se configuran como los principales enclaves de origen y destino del tráfico de mercancías en los que se produce un mayor grado de intermodalidad de los sistemas de transporte tanto marítimo, aéreo, viario como ferroviario.

Por su concentración de infraestructuras y actividad logística, constituyen la estructura primaria de la red.

EI PISTA identifica como tales los siguientes:

- Nodo Logístico del Campo de Gibraltar.

${ }^{3}$ El primer Libro Blanco de la Comisión, publicado en 1992, recoge por primera vez la política comunitaria sobre la materia que continúa con mayor desarrollo en el segundo Libro Blanco de 2001 "la política Europea de Transportes de cara al 2010: la hora de la verdad" y en su revisión de 2006. 
- Nodo Logístico de Huelva.

- Nodo Logístico de Bahía de Cádiz

- Nodo Logístico de Almería

- Nodo Logístico de Motril.

- Nodos interiores: desempeñan funciones de puertos secos para la distribución de cargas desde y hacia el interior de España y Europa, por lo que han de local izarse en zonas estratégicas en cuanto a su dotación de infraestructuras viarias y ferroviarias.

Los nodos interiores identificados por el Plan son los siguientes:

- Nodo Logístico de Sevilla.

- Nodo Logístico de Granada.

- Nodo Logístico de Córdoba.

- Nodo Logístico de Jaén.

- Nodo Logístico Área Central de Andalucía

En la actualidad, se encuentran en servicio un total de 10,6 millones de $\mathrm{m}^{2}$ de superficie específicamente logística que se concentran en su mayor parte en el sistema de nodos portuarios.

Los objetivos principales de esta red de áreas logísticas pueden resumirse del modo que sigue:

- Garantizar el funcionamiento eficiente y sostenible del sector del transporte.

- Favorecer el sistema de transporte intermodal.

- Potenciar el desarrollo de servicios logísticos integrados de forma que fomenten la competitividad.

- Desarrollar la red mediante instrumentos públicos de planificación.

- Favorecer los mecanismos de cooperación entre los agentes públicos y privados para su constitución y explotación.

En definitiva, la logística se configura como una actividad cuyas funciones trascienden los sistemas de infraestructuras reticulares y nodales tradicionales exigiendo un nuevo tipo de infraestructura -las áreas logísticas- en las que se concentren instalaciones y servicios que aporten vaIor añadido a las mercancías, al tiempo que faciliten las operaciones de carga y descarga y proporcionen servicios a los distintos agentes del transporte. 


\subsubsection{Las Plataformas Logísticas}

Con el nombre de nodo o plataforma logística se definen aquellos puntos o áreas de ruptura de la cadena de transporte y logística en los que se concentran actividades y funciones técnicas y de valor añadido.

La función de estas plataformas logísticas ha evolucionado a lo largo de los años, al igual que lo ha hecho su propia denominación -hace 30 años no se hablaba de plataformas logísticas, sino de centros de carretera o centros de mercancías- los agentes implicados en su desarrollo y el proceso de promoción e implementación. De esta forma, en la actualidad se caracterizan por su vinculación intrínseca a la intermodalidad y al desarrollo del transporte combinado a escala europea.

La denominación de plataforma logística establecida por Europlatforms en $1992^{4}$ señala como sus principales características las siguientes:

- Es una zona delimitada en el interior de la cual se ejercen, por diferentes operadores, todas las actividades relativas al transporte, a la logística y a la distribución de mercancías, tanto para el tránsito nacional como internacional.

- Los operadores que desarrollan su actividad en estas áreas, pueden ser propietarios, concesionarios, cesionarios, arrendatarios o superficiarios de los edificios y naves que hayan sido construidos en las mismas ( almacenes, centros de grandes cargas, zonas de almacenaje, oficinas, aparcamientos, etc...)

- Estas plataformas logísticas podrán ser tanto de carácter público como privado, si bien en el primero de los casos habrá de garantizarse el cumplimiento del principio de libre competencia, permitiendo el acceso a todas las empresas que desarrollen las actividades antes expuestas. Además, deberán de estar dotadas de los equipamientos colectivos necesarios para el buen funcionamiento de las actividades desarrolladas en las mismas y comprender servicios comunes para las personas y para los vehículos de los usuarios.

- Están obligatoriamente gestionadas por una única entidad, ya sean públicas o privadas.

${ }^{4}$ Europlatforms, establecida en 1991, es la asociación europea de plataformas logísticas. Está compuesta de alrededor de 60 empresas que han puesto en marcha y gestionan plataformas logísticas por toda Europa en las que operan más de 1.200 empresas del sector del transporte y de la logística. 
Las ventajas que ofrecen estas plataformas son principalmente las siguientes:

- Instalaciones físicas diseñadas específicamente para las actividades que comprenden.

- Infraestructuras y telecomunicaciones con capacidad suficiente y con disponibilidad de conexiones telemáticas inmediatas.

- Zonas de maniobra y viales de acceso adecuado para la circulación de los vehículos.

- Excelente ubicación respecto a las áreas poblacionales e industriales, con posibilidades de intermodalidad.

- Establecimiento junto con otras empresas del sector, lo que permite su interrelación.

- Servicios de mantenimiento, alumbrado, limpieza, etc... con menor coste.

- Vigilancia y seguridad en todas las instalaciones, lo que permite prescindir de sistemas individuales de seguridad, contribuyendo a la creación de un entorno empresarial de calidad y a la mejora de la imagen de las empresas instaladas.

- Disponibilidad de servicios complementarios (talleres, entidades bancarias y de seguros, etc...) que operan como un factor diferencial de especial importancia en la conformación de una imagen de marca.

Por otra parte, la desocupación de suelo urbano gracias a la relocalización de empresas del sector en las plataformas, origina diversas mejoras en el ámbito urbano tales como la sustitución por usos urbanos más adecuados (residencial, terciario), revalorización de suelos, mejoras de áreas degradadas y condiciones privilegiadas de accesibilidad, entre otras. Asimismo, se produce una reducción de los costes de transporte y un importante beneficio económico para la colectividad.

Tradicionalmente, dentro del concepto de plataformas logísticas se distinguen dos tipos según operen con uno o más modos de transporte:

a. Plataformas logísticas con un solo modo de transporte:

a.1.Centros de carretera o centros de servicios al transporte: Son plataformas constituidas fundamentalmente por un área de servicios para empresas del transporte por carretera que en algunos casos incluyen una pequeña área logística subordinada a la de servicios. Funcionan vinculadas al modo de transporte por carretera. 
a.2. Áreas de almacenamiento y distribución: Plataformas logísticas, principalmente de carácter regional, con todos los servicios y equipamientos necesarios para llevar a cabo las actividades de almacenamiento y distribución. En ellos se implantan tanto los departamentos logísticos de empresas productoras como empresas de distribución, operadores logísticos y empresas de almacenaje, entre otras.

a.3.Centros de transporte: Estas plataformas logísticas se centran principalmente en el transporte por carretera, ya operen en un ámbito metropolitano o provincial. Suelen estar formadas por un área logística y otra de servicios tanto a las personas como a los vehículos. Su finalidad transciende la de dar un servicio a los transportistas de carretera, que es la finalidad perseguida por los centros de carretera, pues se extienden a todas las empresas del sector transporte, contando para ello con un área logística bien consolidada y un área de servicios completa que incluye tanto a los servicios a las personas y a los vehículos, como centros administrativos de las empresas del transporte, centros de contratación de carga, etc... Es la denominación utilizada por la Ley 5/ 2001, aunque con un contenido mucho más amplio que el ofrecido en su acepción más tradicional.

\section{b. Plataformas Logísticas con más de un modo de transporte:}

- Zonas de actividades logísticas portuarias: Plataformas logísticas vinculadas a puertos que albergan actividades de segunda y tercera línea portuaria generalmente dedicadas a actividades logísticas de mercancías marítimas. Su implantación responde a los requerimientos de manipulación y distribución de mercancías marítima hacia y desde el hinterland portuario.

- Centros de carga aérea: Están especializadas en el intercambio modal aire-tierra y el tratamiento de mercancías de carga aérea. Cuentan con un área multimodal de primera línea y pueden estar dotadas de una zona logística de segunda línea que comprende todas las actividades destinadas a prestar servicios adicionales al despacho de carga (almacenamiento para transitarios y operadores logísticos, oficinas operacionales) y una zona de servicios más o menos unitaria. En algunos casos cuentan con área de distribución para empresas cargadoras.

- Puertos secos: son un tipo de terminal intermodal situados en el interior que conectan a través de la red ferroviaria con el puerto de origen o destino, de ahí su denominación, al manipular tráfi- 
cos portuarios en una zona interior. Constan de un área intermodal ferrocarril-carretera como área funcional principal, si bien suelen estar asociados a otras áreas funcionales, principalmente un parque de distribución, y un área de servicio.

- Plataformas logísticas multimodales: Son las plataformas con mayor complejidad funcional y están formadas por diversas áreas funcionales en las que son claves las áreas intermodales ferrocarril-carretera. Poseen áreas logísticas generales y de servicios, pudiendo constar además de áreas especializadas, con áreas monofuncionales, etc. Pueden ser tanto nacionales como regionales.

En el caso de España, se pueden destacar como principales plataformas logísticas las siguientes:

- La Zona de Actividades Logísticas del Port de Barcelona: Es la plataforma logística intermodal del enclave portuario barcelonés, cuya misión radica en ayudar al puerto a generar más tráfico marítimo ofertando servicios logísticos de valor añadido a la mercancía.

Ha sido la primera plataforma logística portuaria establecida en España y su desarrollo se ha convertido en un modelo a seguir en muchos otros entornos portuarios dando el nombre genérico a este tipo de instalaciones. La Zona de Actividades Logísticas (ZAL) realiza actuaciones de gestión inmobiliaria, ofreciendo naves logísticas en alquiler en un entorno intermodal y prestando servicios dirigidos no solamente a las empresas sino, sobre todo, a las personas que trabajan en ellas.

Esta ZAL alberga empresas transitarias y logísticas relacionadas con el comercio exterior, tanto nacionales como internacionales, teniendo como principal objetivo coadyuvar al crecimiento del Puerto de Barcelona.

La actividad total que realizan estos clientes genera un movimiento de dos millones y medio de toneladas de mercancías anuales. El 35\% de éstas tienen un origen o final marítimo; el 56\% de las empresas pertenecen a transitarios; el $28 \%$ de las empresas a operadores logísticos; el $9 \%$ a distribuidores dedicados al comercio exterior, y el $7 \%$ a fabricantes de otros sectores.

- Plataforma Logística de Zaragoza (PLAZA): Con una extensión de 12.826.898 $\mathrm{m}^{2}$, la Plataforma Logística de Zaragoza (PLAZA), pro- 
yecto que se encuentra aún en su fase inicial, es el recinto de mayores dimensiones del continente europeo, aunque no toda su superficie está destinada a la actividad logística.

Su gestión, ejecución y promoción están encomendadas a la entidad PLAZA S.A, sociedad en la que participa mayoritariamente el Gobierno de Aragón junto con el Ayuntamiento de Zaragoza y las dos principales entidades de ahorro de la Comunidad Autónoma, Ibercaja y la Caja de Ahorros de la Inmaculada.

La principal característica de PLAZA es que está basada en un centro intermodal de transportes (ferrocarril, carretera y avión) con conexiones con los centros de producción y consumo europeos más relevantes.

Esta intermodalidad refuerza los valores de localización y centralidad del recinto, completamente abierto a empresas que participen en actividades relacionadas con la logística, a quienes PLAZA atiende con una serie de equipamientos colectivos y servicios comunes que multiplican la rentabilidad de su ubicación. La intermodalidad supone, además, unas sinergias decisivas en las cadenas logísticas que todos los operadores necesitan.

- Zona de Actividades Logísticas del Campo de G ibraltar: Proyecto en fase de desarrollo, declarado de interés autonómico por la Ley 5/ 2001, de 4 de junio reguladora de las áreas de transporte de mercancías de la Comunidad Autónoma Andaluza y previsto en el citado Plan Director de Infraestructuras de Andalucía aprobado mediante Decreto 108/ 1999 de 11 de mayo.

Se configura como una infraestructura logística de primer orden a escala nacional e internacional, apoyada en las excelentes condiciones de su puerto y con las características de centro multimodal, capaz de acoger un amplio abanico de funciones logísticas estratégicas y servir como elemento de conexión entre las instalaciones portuarias y la comarca.

Esta actuación se desarrolla en un ámbito territorial de aproximadamente 293 has que la configuran como un núcleo de centralidad logística perteneciente al nodo logístico del Campo de Gibraltar. 
Su gestión viene encomendada a la entidad "Zal Bahía de Algeciras S.A.", sociedad participada mayoritariamente por la Junta de Andalucía a través de la Agencia Pública de Puertos de Andalucía y la Agencia de Innovación y Desarrollo de Andalucía.

- Área de las Aletas, en Puerto Real (Cádiz): Proyecto de promoción y desarrollo de diversos usos logísticos, tecnológicos, científicos y comerciales en el área de "Las Aletas", Puerto Real, en la Bahía de Cádiz, declarada de interés autonómico por la Ley 21/ 2007 de 18 de diciembre de Régimen Jurídico y Económico de los Puertos de Andalucía.

La zona logística de las Aletas cuenta con una superficie total de 527 has. de las que 158,90 H as se dedican al Área Logística Intermodal.

La gestión de este área le corresponde a un consorcio constituido por la Administración General del Estado y la Junta de Andalucía.

\section{II. ÁREAS DE TRANSPORTE DE MERCANCÍAS}

Una vez que ha quedado puesta de manifiesto la trascendencia que, en el marco de una economía globalizada, adquieren las plataformas logísticas como instrumento clave de la competitividad y desarrollo de una región o país, veamos a continuación la regulación que, en el ámbito autonómico, tienen las denominadas áreas de transporte de mercancías y sus implicaciones en el ámbito de la planificación territorial y urbanística.

\section{II.1.Concepto de áreas de transporte de mercancías}

El artículo 6 de la Ley 5/ 2001 de 4 de junio reguladora de las áreas de transportes de mercancías en la Comunidad Autónoma de Andalucía, las define como "aquellas zonas debidamente delimitadas, integradas por espacios continuos o discontinuos, destinadas a prestar servicios a los usuarios y a las empresas del sector del transporte, así como a facilitar la localización de éstas, en el ámbito de las cuales los distintos operadores pu eden realizar, autónoma, conjun ta o coordinadamente, actividades relativas al transporte, a la logística y a la distribución y contratación de mercancías"

La definición ofrecida por el citado artículo 6 se aproxima mucho más al concepto de centro que al de estación de transporte de mercancías, como se 
verá a continuación al analizar de forma separada los diferentes elementos que la integran:

\section{Zonas debidamente delimitadas, integradas por espacios continuos o disconti- nuos:}

A este respecto, el artículo 8 de la ley relativo a los centros de transporte de mercancías, establece que los mismos son "recintos preferentemente acotados". Aunque el artículo se refiere exclusivamente a los centros de transporte de mercancías, la configuración de los mismos como recintos de tales características es aplicable igualmente a las estaciones de transportes de mercancías.

En el mismo artículo se señala que corresponde al planeamiento urbanístico "determinar, en su caso el grado de accesibilidad de sus diferentes zonas, así como su posible discontinuidad espacial en función de las exigencias derivadas".

En relación a esto último, la ley se está refiriendo fundamentalmente a los centros de transporte de mercancías y no a las estaciones, en la medida en la que es la mayor complejidad de las primeras la que exige hacer referencia tanto a su accesibilidad como a la posible discontinuidad de las zonas que lo conforman. En relación a los centros, basta apuntar que los mismos están integrados por una zona dotacional de dominio público y por espacios de titularidad pública o privada, mientras que las estaciones únicamente disponen de una zona dotacional. No obstante, sobre este punto se insistirá más adelante.

\section{Destinadas a prestar servicios a los usuarios y a las empresas del sector del trans- porte así como a facilitar la localización de éstas.}

En efecto, el artículo 8 en su apartado tercero enumera de modo meramente ejemplificativo los siguientes servicios: gestión, información, oferta, organización y contratación de cargas, ruptura y distribución de las mismas, almacenamiento de mercancías, estacionamien to y comunicaciones, así como todas aquellas otras prestaciones que redunden en la mayor segu ridad y comodidad del transportey sus u suarios, tales como, entre otros, suministro de carburantes, pernoctación, restauración, re paración de vehículos.

En definitiva, las áreas de transportes de mercancías cumplen, fundamentalmente, las siguientes funciones:

- Prestación de servicios a las empresas del sector transporte. 
- Facilitar la localización de las empresas dedicadas al transporte, la logística, y la distribución.

En el ejercicio de dichas funciones, estas áreas se encuentran abiertas, en general, a todos los transportistas.

Asimismo y en lo que a las estaciones de transporte se refiere, el artículo 10 dispone expresamente cómo en las estaciones de transporte de mercancías también podrán prestarse, en función de las necesidades de las empresas y usuarios del transporte del municipio o área en que se encuentren, los servicios señalados en el artículo 8.3 que resulten adecuados a su ámbito y características.

En el ámbito de las cuales los distintos operadores pueden realizar, autónoma, conjunta o coordinadamente, actividades relativas al transporte, a la logística y a la distribución y contratación de mercancías.

En relación a este último inciso, basta remitirse a las consideraciones efectuadas al inicio de este estudio sobre las distintas actividades susceptibles de desarrollo en estas áreas.

Para concluir y aún tratándose de cuestiones que se desarrollan en posteriores epígrafes, basta señalar que la titularidad y dirección de las áreas de transporte de mercancías corresponden a la Administración autonómica, siendo la gestión competencia de la Agencia Pública de Puertos de Andalucía (APPA), todo ello sin perjuicio de las fórmulas de participación tanto públicas como privadas que pudieran adoptarse conforme a lo dispuesto en la Ley 5/ 2001.

\section{II.2. Clases: centros y estaciones de transporte de mercancías}

Dentro del concepto de áreas de transportes de mercancías, la Ley 5/ 2001 distingue entre los centros y las estaciones de transporte de mercancías. Aunque algunas de las diferencias entre ambos ya se han puesto de manifiesto en el apartado anterior y teniendo en cuenta que, por su mayor complejidad y trascendencia, el presente estudio se centra fundamentalmente en los primeros, veamos brevemente las principales diferencias entre unos y otras:

\section{II.2.1. Centros de transporte de mercancías}

La ley define en su artículo 8 a los centros de transporte de mercancías como aquellas áreas de transporte de mercancías en las que, tanto por las exi- 
gencias derivadas de la dimensión y calidad de las prestaciones demandadas por los usuarios y empresas del sector como por su función cualificadora de la ordenación territorial, se requiere el establecimiento de una plataforma logística compleja, integradora de las empresas del sector transporte y de los espacios dotacionales públicos destinados a prestar servicios al mismo.

Estos centros, que pueden ser polinucleares, tienen por objeto atender las necesidades cuantitativas y cualitativas requeridas por la ordenación territorial y el sistema de transporte, y se rigen por los principios de unidad y coordinación en la prestación de servicios.

Dichos centros están integrados por dos siguientes zonas:

- Una zona dotacional, de naturaleza demanial, destinada a la prestación del servicio público al transporte de mercancías, en los términos descritos en el apartado anterior.

- Una zona integrada por espacios de titularidad pública o privada, destinada al establecimiento y desarrollo por las empresas del sector del transporte de sus propias actividades e instalaciones.

\section{II.2.2. Estaciones de transporte de mercancías}

La regulación contenida en la Ley 5/ 2001 de las estaciones de transporte de mercancías es muy similar a la establecida en la LOTT, y así, el artículo 10 las define como áreas de transporte integradas únicamente por una zona demanial destinada a concentrar las salidas y llegadas a una población o área territorial de los vehículos de transporte, así como a facilitar la coordinación intermodal y la mejora de las condiciones del transporte, la circulación y el tráfico en aquéllas.

Con un criterio de delimitación negativo, la ley especifica que no tendrán esta consideración los terrenos e instalaciones destinados únicamente a garaje, estacionamiento de vehículos o almacenamiento de mercancías, que no posean las características mínimas antes reseñadas. Aún más, dispone que en el supuesto en el que su utilización sea pública y su funcionamiento afecte negativamente a la ordenación del transporte o del tráfico, el órgano administrativo competente podrá imponer limitaciones a su establecimiento o utilización, prohibirlos o condicionarlos a su transformación en estaciones de transporte de mercancías.

En estas estaciones, como ya se expuso más arriba, podrán prestarse los servicios previstos en el apartado 3 del artículo 8 en función de las necesida- 
des de las empresas o usuarios del transporte del municipio o área en que se encuentren.

Mientras que los centros de transportes de mercancías pueden ser de interés autonómico o de interés local, las estaciones pueden tener carácter municipal o supramunicipal. No obstante, estas cuestiones se tratarán más adelante en el epígrafe relativo a la promoción y gestión.

Como puede observarse, la ley se refiere exclusivamente a los centros y estaciones de transporte de mercancías, sin hacer referencia a otras clases de plataformas logísticas como puedan ser las zonas de actividades logísticas. Este hecho no debe de interpretarse como una manifestación de la ley de optar por regular única y exclusivamente los centros de transporte de mercancías en su definición más tradicional, ofrecida más arriba. Muy al contrario, parece que la intención del legislador ha sido la de englobar, bajo aquélla denominación, los distintos tipos de plataformas logísticas. En este sentido, la Ley 5/ 2001 debería de haber sido más ambiciosa, contemplando entre sus determinaciones una definición clara y comprensiva de las distintas tipologías que pueden adoptar lo que tradicionalmente se ha venido a denominar como plataforma logística.

\section{ADMINISTRACIÓN COMPETENTE. PROMOCIÓN Y ESTABLE- CIMIENTO DE LAS ÁREAS DE TRANSPORTE DE MERCANCÍAS}

\section{III.1. Estatuto de Autonomía para Andalucía}

El Estatuto de Autonomía de Andalucía aprobado mediante Ley O rgánica $2 / 2007$, dedica el Título II a la regulación de las competencias de la Comunidad Autónoma Andaluza.

El artículo 42 del Título I clasifica dichas competencias en exclusivas, compartidas y ejecutivas, siempre dentro del respecto a lo dispuesto en la Constitución y en el Estatuto, ofreciendo una definición de lo que debe entenderse por cada una de ellas.

- Competencias exclusivas: son aquellas que comprenden la potestad legislativa, reglamentaria y la función ejecutiva, íntegramente y sin perjuicio de las competencias atribuidas al Estado en la Constitución.

En el ámbito de sus competencias exclusivas, el derecho andaluz es de aplicación preferente en su territorio sobre cualquier otro, teniendo en estos casos el derecho estatal carácter supletorio. 
- $\quad$ Competencias compartidas: las que comprenden la potestad legislativa, la potestad reglamentaria y la función ejecutiva, en el marco de las bases que fije el Estado en normas con rango de ley, excepto en los supuestos que se determinen de acuerdo con la Constitución.

En el ejercicio de estas competencias, la Comunidad Autónoma puede establecer políticas propias.

- Competencias ejecutivas: son las que comprenden la función ejecutiva que incluye la potestad de organización de su propia Administración y, en general, aquellas funciones y actividades que el ordenamiento atribuye a la Administración Pública y, cuando proceda, la aprobación de disposiciones reglamentarias para la ejecución de la normativa del Estado.

- Finalmente, se refiere el estatuto a las competencias en relación con la aplicación del derecho comunitario, que comprenden el desarrollo y la ejecución de la normativa de la Unión Europea cuando afecte al ámbito de las competencias de la Comunidad Autónoma.

La referencia a esta clasificación es importante en la medida en la que el artículo 64 del Estatuto que regula las competencias autonómicas en materia de transportes y comunicaciones, distingue entre las que le corresponden con carácter exclusivo y las que tienen un carácter ejecutivo.

Así, corresponde a la Comunidad Autonómica Andaluza la competencia exclusiva sobre las siguientes materias:

- Red viaria de Andalucía, integrada por ferrocarriles, carreteras y camin os, y cualquier otra vía cu yo itinerario se desarrolle íntegramente en territorio andaluz.

- Transporte marítimo y fluvial de person as y mercancías que tran scurra ínte gramente den tro de las aguas de Andalucía.

- Tran sportes terrestres de personas y mercan cías por carretera, ferrocarril, cable o cualquier otro medio cuyo itin erario se desarrolle íntegramente en territorio andaluz, con independencia de la titularidad de la infraestructura sobre la que se desarrolle.

- Centros de transporte, logística y distribución localizados en Andalucía, así como sobre los operadores de las actividades vinculadas a la organización del transporte, la logística y la distribución localizadas en Andalucía.

- Puertos de refugio, puertos y aeropuertos deportivos y, en gen eral, puertos, aeropuertos y helipu ertos y demás infraestructuras de tran sporte en el territorio de Andalucía que no ten gan la calificación legal de interés gen eral del Estado. 
Esta atribución de competencias en el ámbito autonómico es plenamente respetuosa con lo dispuesto en el artículo 149 de la Constitución española que establece en su apartado tercero que aquellas materias no atribuidas expresamente al Estado en el apartado primero puedan ser asumidas por las Comunidades Autónomas en virtud de sus respectivos estatutos.

Concretamente, y en lo que a materia de transportes se refiere, los apartados $20^{\circ}$ y 21 을 atribuyen al estado la competencia exclusiva sobre lo siguiente:

- $\quad$ Apartado 20: Marina mercante y abanderamiento de buques; iluminación de costas y señales marítimas; puertos de interés general; aeropuertos de interés general; control del espacio aéreo, tránsito y transporte aéreo, servicio meteorológico y matriculación de aeronaves.

- Apartado 21: Ferrocarriles y transportes terrestres que transcurran por el territorio de más de una Comunidad Autónoma; régimen general de comunicaciones; tráfico y circulación de vehículos a motor; correos y telecomunicaciones; cables aéreos, submarinos y radiocomunicación.

En relación con las competencias ejecutivas reconocidas a la Comunidad en materia de transportes y comunicaciones, corresponden a la misma las siguientes:

1. a Puertos y aeropuertos con calificación de interés general, cuando el Estado no se reserve su gestión directa.

2. a O rdenación del transporte de mercancías y personas que tengan su origen y destino dentro del territorio de la Comunidad Autónoma, cualquiera que sea el titular de la infraestructura.

Asimismo, conviene hacer referencia a otras cuestiones contenidas en el citado artículo 64, al objeto de ofrecer el escenario sobre el que el Estatuto de Autonomía establece el marco competencial de la Comunidad sobre estas materias.

Así, se asegura la participación de la Comunidad Autónoma en los siguientes términos:

- Planificación y gestión de las infraestructuras relativas a la red ferroviaria así como en los organismos de ámbito suprautonómico que ejerzan funciones sobre las infraestructuras de transporte, en ambos 
casos cuando se trate de infraestructuras de titularidad estatal situadas en Andalucía en los términos previstos en la legislación del Estado.

- Planificación y programación de puertos y aeropuertos de interés general en los términos que determine la normativa estatal.

- Establecimiento de los servicios ferroviarios que garanticen la comunicación con otras Comunidades Autónomas o con el tránsito internacional de acuerdo con lo previsto en el Título IX.

Asimismo, se requiere informe previo de la Comunidad Autónoma en los siguientes supuestos:

- Sobre la calificación de interés general de un puerto, aeropuerto u otra infraestructura de transporte situada en Andalucía pudiendo participar en su gestión o incluso asumirla, de acuerdo con lo previsto en las leyes. Tratándose de una infraestructura de titularidad autonómica, se requerirá informe previo de la Comunidad y su ejecución se llevará a cabo mediante un convenio de colaboración.

- Sobre la integración de líneas o servicios de transporte que transcurran íntegramente por Andalucía en líneas o servicios de ámbito superior.

\section{III.2. La Ley 5/ 2001 reguladora de las áreas de transportes de mercancías en la Comunidad Autónoma Andaluza}

El contenido de la Ley 5/ 2001 de 4 de junio, es plenamente respetuoso con la distribución de competencias fijada tanto en la Constitución como en el Estatuto de Autonomía y así, el artículo 11 de la misma atribuye a la Administración autonómica y local la iniciativa para la promoción y establecimiento de las áreas de transporte de mercancías, todo ello sin prejuicio de la cooperación de otras entidades públicas o particulares que actuarán, en todo caso, con sujeción a lo dispuesto en la ley.

En este sentido, el mismo artículo se refiere a la utilización de convenios y a la constitución de consorcios como instrumentos mediante los que podrá articularse la cooperación entre las Administraciones y entidades públicas o privadas para la promoción, establecimiento y gestión de las áreas de transporte de mercancías (Exposición de Motivos), sin perjuicio de acudir a las demás fórmulas previstas por la legislación aplicable.

La referencia al principio de coordinación para la promoción, establecimiento y gestión de estas áreas es constante a lo largo de todo el texto de la 
ley. Ya en la Exposición de Motivos se destaca expresamente la importancia de este principio que se reitera a lo largo de otros preceptos de la misma. Concretamente el Título Preliminar, en su artículo 3o dispone que "Los órganos y entidades competentes de la Administración de la Comunidad Autónoma de Andalucía fomentarán la máxima cooperación y participación de las Entidades L ocales interesadas en orden a la planificación, promoción, establecimiento y explotación de las áreas de transporte de mercan cías"

Por su parte, el artículo 12 relativo al procedimiento de aprobación del establecimiento de los centros de transporte de mercancías se refiere, al señalar el contenido mínimo del Plan Funcional, a "las fórmulas de cooperación e integración de otras Administraciones y de la iniciativa privada en orden a la promoción, construcción y gestión del centro"

De igual modo, el artículo 13 sobre iniciativa, promoción, establecimiento y gestión de las estaciones de transporte de mercancías de ámbito supramunicipal, establece que estas actuaciones podrán ser asumidas, entre otras, por las entidades de carácter consorcial o asociativo que puedan resultar de los convenios de cooperación interadministrativa que se suscriban.

Asimismo, el artículo 14 sobre cooperación para el establecimiento de las áreas de transporte de mercancías de interés local, prevé la aportación financiera de la Administración de la Comunidad Autónoma para la construcción y desarrollo de las instalaciones de los centros y de las estaciones de transporte de mercancías de carácter local y supramunicipal, en cuya gestión podrá participar en los términos en los que establezca el correspondiente convenio que se suscriba al efecto.

También establece la posibilidad de que la Administración de la Comunidad Autónoma y las Diputaciones Provinciales asuman la iniciativa, promoción, establecimiento y gestión de los centros y estaciones de transporte de mercancías de carácter local y supramunicipal cuando, considerándose necesaria su instalación y previo requerimiento de la Administración de la Comunidad Autónoma, las Entidades Locales competentes para ello no hayan ejercido la correspondiente iniciativa.

Volviendo a la competencia para la promoción y establecimiento de las áreas de transporte de mercancías y dejando a un lado el procedimiento de elaboración y aprobación del Plan Funcional como instrumento de planificación sectorial, que será objeto de estudio en el epígrafe VI, la ley distingue según se trate de centros o estaciones de transporte de mercancías. 
Asimismo y respecto de los primeros, la competencia es distinta según se trate de centros de interés autonómico o local, y lo mismo ocurre en el caso de las estaciones de transporte de mercancías, que podrán ser de interés municipal o supramunicipal. De acuerdo con estas premisas, las entidades con competencia para la iniciativa, promoción y establecimiento de los centros y estaciones de transportes de mercancías sería la que sigue:

- Centros de transporte de mercancías:

- De interés autonómico: La Consejería de O bras Públicas y Transportes de la Junta de Andalucía, con carácter exclusivo.

- De interés local:

- Municipal: Los Ayuntamientos interesados.

- Supramunicipal: La entidad local de ámbito superior al municipio que lo promueva o entidad de carácter asociativo constituida al efecto, sin perjuicio de la iniciativa de la Administración autonómica a que se refiere el apartado 2 del artículo 14 sobre cooperación en materia de estaciones y centros de transporte de interés local.

En ambos supuestos, la competencia para la aprobación definitiva del establecimiento de los centros de transporte de mercancías de interés local y autonómico y de su Plan Funcional corresponde a la Consejería de O bras Públicas y T ransportes de la Junta de Andalucía. De no recaer resolución expresa en el plazo de seis meses, el silencio administrativo se entenderá desestimatorio.

- Estaciones de transporte de mercancías:

- De interés municipal: El ayuntamiento interesado.

- De interés supramunicipal: Caben tres posibilidades

- Las entidades locales de ámbito superior al municipio.

- Las entidades de carácter supramunicipal constituidas al efecto por los ayuntamientos interesados.

- Las entidades de carácter consorcial o asociativo que puedan resultar de los convenios de cooperación interadministrativa que se suscriban, en las que también podrán integrarse otras Administraciones y entidades públicas o privadas conforme a lo dispuesto en la legislación que resulte aplicable. 
En estos casos, la aprobación del establecimiento de estos centros corresponde, tratándose de estaciones de interés municipal, al Ayuntamiento que haya asumido la iniciativa y, en las de interés supramunicipal, a la Consejería de O bras Públicas y T ransportes a instancia de cualquiera de las entidades con competencia para su promoción.

\section{III.3. G estión del suelo de las áreas de transporte de mercancías}

El Capítulo II del Título II relativo a "La Planificación Territorial y DesarroIlo U rbanístico de las Á reas de T ransporte de M ercancías", se refiere a la gestión del suelo de dichas áreas, distinguiendo según se trate de los centros o de las estaciones de transportes de mercancías.

En relación con los primeros, dispone el artículo 18 de la citada ley que la misma se llevará a cabo, siempre conforme a lo previsto en la legislación urbanística, de cualquiera de las siguientes formas:

- Mediante el sistema de expropiación: Este sistema aparece regulado en la Sección segunda Capítulo II del Título IV bajo la rúbrica "L a ejecución de los instrumentos de planeamiento", en los artículos 114 y siguientes de la Ley 7/ 2001 de 17 de diciembre de Ordenación U rbanística de Andalucía ( LOUA). La elección de este sistema de actuación es el primero de los supuestos previstos en el artículo 160 de la ley para proceder a la expropiación forzosa por razón de urbanismo.

En éste, los terrenos no dotacionales que integran los centros de transporte estarán sujetos en su disposición, administración y uso al Derecho privado, pudiéndose integrar en el patrimonio de la entidad que tenga confiada la promoción de aquél, es decir, la Agencia Pública de Puertos de Andalucía, que podrá proceder, en su caso, a la enajenación de dichos terrenos. Todo ello, sin perjuicio de las técnicas, tanto de Derecho público como de Derecho privado que se habiliten para asegurar la permanencia de los usos, el régimen y las finalidades propios de dichos centros.

- Mediante otros sistemas de actuación que integren la participación de la iniciativa privada, siempre que se garantice el carácter de conjunto y la gestión unitaria de centro. Es decir, a través de los sistemas de cooperación y compensación respectivamente regulados en la sección tercera y cuarta de Capítulo II del Título IV. 
No obstante, cualquiera que sea la forma de gestión utilizada, los terrenos dotacionales de carácter público integrados en los centros de transportes de mercancías, así como el viario interior del recinto, se integrarán en el dominio público de la Administración o Entidad pública a la que corresponda la titularidad del centro de transporte y se gestionará por el órgano encargado de su dirección y administración.

Mención especial merece el artículo 20 relativo a la gestión del suelo de los centros de transportes de mercancías de interés autonómico, por tener este carácter la totalidad de los centros promovidos en la comunidad andaluza.

El artículo 20 de la Ley 5/ 2001 dispone que “La aprobación del planeamiento territorial o urbanístico preciso para la implantación de un centro de transporte de mercancías de interés autonómico implicará la declaración de utilidad pública de las obras y la necesidad de ocupación de los terren os y edificios correspondientes, pudien do la Administración de la Comunidad Autón oma de Andalucía asumir la condición de Administración actuante, acordar expropiaciones urbanísticas y proceder al desarrollo de cualquier sistema de actuación urbanística. A estos efectos, la Consejería competente podrá, previo informe de las Entidades L ocales afectadas, que se en ten derá favorable si no se emite en el plazo de un mes, delimitar áreas de reserva de terrenos para su expropiación y para el ejercicio por la Comunidad Autón oma de los derechos de tanteo y retracto, así como unidades de ejecución, conforme al procedimiento establecido en la legislación urbanística"

- Aprobación del planeamiento territorial o urbanístico: En este punto hay que distinguir entre ambos instrumentos de planeamiento. En cuanto a los primeros, tienen carácter normativo y sus determinaciones, tratándose de los planes territoriales de las comunidades autónomas, se imponen jerárquicamente a los planes de ordenación territorial inferiores y al planeamiento urbanístico. En relación con éstos últimos, los mismos se configuran como la pieza esencial de la ordenación general e integral del territorio del municipio y su naturaleza también es normativa, si bien habrán de respetar las directrices y determinaciones de los instrumentos de planificación territorial. En definitiva, estos planes constituyen uno de los presupuestos objetivos que legitiman la ejecución del planeamiento, en este caso, la implantación de un centro de transporte de mercancías de interés autonómico.

- Implicará la declaración de utilidad pública de las obras y la necesidad de ocupación de los terrenos y edificios correspondientes, pudiendo la Administración de la Comunidad Autónoma de Andalucía asumir la condición de 
Administración actuante, acordar expropiaciones urbanísticas y proceder al desarrollo de cualquier sistema de actuación urbanística.

- En definitiva, la ley otorga dos efectos a la declaración de interés autonómico que son tanto la declaración de utilidad pública como la necesidad de ocupación.

- La facultad que tiene la Administración autonómica de asumir la condición de Administración actuante le permite, además de acordar expropiaciones urbanísticas, (entendidas, según la jurisprudencia del Tribunal Supremo, como aquéllas que tienen como finalidad la ejecución del planeamiento urbanístico o que están motivadas por el incumplimiento de los deberes de esta clase, si bien a estos dos supuestos prototípicos la legislación autonómica ha sumado otros al definir la causa expropriandi en el ámbito del urbanismo) desarrollar cualquier otro sistema de actuación, a saber, el sistema de compensación y el de cooperación, siempre de forma motivada y teniendo en cuenta las prioridades y necesidades del desarrollo del proceso urbanizador, la capacidad de gestión y los medios económico-financieros con que efectivamente cuente.

- A estos efectos, la Consejería competente podrá, previo informe de las Entidades $L$ ocales afectadas, que se entenderá favorable si no se emite en el plazo de un mes, delimitar áreas de reserva de terrenos para su expropiación y para el ejercicio por la Comunidad Autón oma de los derechos de tanteo y retracto, así como unidades de ejecución, conforme al procedimien to establecido en la legislación urbanística.

La finalidad de la delimitación de las áreas de reservas de terrenos consiste en establecer superficies de suelo de posible adquisición para la constitución o ampliación de patrimonio público de suelo, lo que permite desarrollar una política de promoción de suelo público con cierta autonomía respecto del planeamiento urbanístico.

Si tradicionalmente la reserva opera sobre los terrenos calificados por el planeamiento como suelo urbanizable no programado o no urbanizable que no esté sujeto a especial protección, tratándose de la legislación autonómica, la LOUA no establece limitación alguna en cuanto a la clase de suelo. Así se recoge en el artículo 73 de dicha ley que establece que "Los Planes de O rdenación del Territorio, las activida- 
des de planificación de la Junta de Andalucía que ten gan la consideración de Planes con Incidencia en la Ordenación del Territorio y el Plan General de Ordenación U rbanística podrán establecer en cualquier clase de su elo reservas de terrenos de posibleadquisición para la constitución o ampliación de los patrimonios públicos de suelo. A sí, en el apartado 2, especifica el objeto de tales reservas según se hubiera calificado el suelo de urbano, urbanizable o no urbanizable"

El artículo 20 de la Ley 5/ 2001 que ha de ponerse en relación con el artículo 73 de la LOUA establece en su apartado tercero que en ausencia de dichos planes o de previsión en los mismos de las reservas de terrenos para los patrimonios públicos de suelo, podrán proceder a su delimitación, además de los municipios, la Consejería competente en materia de urbanismo, en suelo no urbanizable, mediante la aprobación al efecto de un plan especial; y en suelo urbanizable mediante el procedimiento de delimitación de reservas de terrenos, previa información pública, audiencia del municipio o municipios y propietarios afectados por plazo común de veinte días, y publicación en el Boletín O ficial de la Junta de Andalucía.

Señala además que el establecimiento o la delimitación de las reservas de terrenos con la finalidad expresada en los apartados anteriores comporta:

- Por un lado, la declaración de la utilidad pública a efectos de expropiación forzosa por un tiempo máximo de cinco años, prorrogable por una sola vez por otros dos; debiendo iniciarse el expediente expropiatorio en el curso del referido plazo. La prórroga deberá fundarse en causa justificada y acordarse por la Administración competente, previa información pública y audiencia a los propietarios afectados por plazo común de veinte días, procediéndose a su publicación en el Boletín Oficial correspondiente. En suelo urbano o urbanizable sectorizado, implicará además, en su caso, la sustitución o fijación del sistema de actuación previsto para la ejecución de la unidad de ejecución por expropiación.

- Por otro, la sujeción de todas las transmisiones que se efectúen en las reservas de terrenos a los derechos de tanteo y retracto previstos en dicha ley en favor de la Administración que proceda.

Asimismo, establece la posibilidad de que mediante convenio de colaboración, los municipios y la Administración de la Junta de Anda- 
lucía puedan acordar la gestión concertada de las reservas de suelo, pudiendo adquirirse bienes en reservas delimitadas por cualquiera de estas Administraciones.

Respecto del informe a que se refiere el artículo 20 de la Ley 5/ 2001, si bien su solicitud tiene carácter preceptivo, su contenido, ya sea favorable o desfavorable, no vincula a la Administración.

Finalmente y en relación con la delimitación de las unidades de ejecución, la LOUA se remite a lo dispuesto en la legislación urbanística. En este sentido, estas unidades de ejecución se configuran como las unidades esenciales de ejecución del modelo previsto en el plan, debiendo de estar configurados de modo que permitan la aplicación efectiva del principio de reparto equitativo de cargas y beneficios entre los titulares afectados mediante el cumplimiento de los deberes de cesión, equidistribución y urbanización. Asimismo, deberán de tener entidad suficiente para justificar la autonomía de actuación que suponen.

En cuanto a las estaciones de transporte de mercancías, el artículo 19 de la ley establece que la obtención, urbanización y gestión de los suelos necesarios para su establecimiento se efectuará conforme a lo previsto en la legislación urbanística para las dotaciones.

En este sentido, el artículo 139 de la LOUA en su apartado primero se ocupa de la obtención de terrenos para dotaciones que, aunque no lo diga expresamente, se entiende que son públicas. Así, establece cuatro procedimientos para la obtención, en fase de ejecución del planeamiento, de suelo destinado a dotaciones públicas:

- Mediante el desarrollo del sistema de actuación correspondiente.

- A través de la técnica de las transferencias de aprovechamiento urbanístico.

- Mediante la expropiación forzosa (no entendida como sistema de actuación)

- Por ocupación directa.

\section{III.4. T itularidad, dirección y gestión de las áreas de transportes de mercancías}

El Título III de la Ley 5/ 2001 se refiere a la gestión de las áreas de transportes de mercancías a través de dos artículos: el artículo 21 sobre titularidad, 
dirección y gestión de dichas áreas, y el artículo 22 relativo a los centros de transporte de mercancías de interés autonómico.

El primero de estos artículos se centra, fundamentalmente, en el mantenimiento y conservación de estas áreas. En este sentido dispone que corresponde a la Administración o Entidad pública bajo cuya titularidad y responsabilidad se desarrolle la promoción, establecimiento y construcción de dichas áreas, sin perjuicio de que aquélla pueda confiar el desarrollo efectivo de dichas funciones a otras entidades públicas o privadas, conforme a la legislación vigente, las siguientes funciones:

- Las de dirección y control.

- $\quad$ El mantenimiento y conservación de sus obras, infraestructuras e instalaciones.

- La gestión de sus dotaciones y servicios.

Asimismo, y con el objetivo de asegurar el adecuado funcionamiento y utilización de dichas áreas, los concesionarios y usuarios de las áreas de transporte de mercancías y, en su caso, los propietarios de las parcelas susceptibles de titularidad privada integrados en las mismas, estarán sometidos a los Reglamentos de Régimen Interior y de Servicio que se aprueben por la Administración o Entidad pública titular de aquéllas, con la participación de las empresas y profesionales que en ellas operen.

Junto con esta actividad rectora que se atribuye expresamente a la Administración o, en su caso, a las entidades a las que ésta confíe el ejercicio de tales funciones, la ley atribuye a los propietarios de las parcelas lucrativas integradas en los centros de transporte, así como a los concesionarios de los espacios dotacionales, la obligación de contribuir a los gastos de conservación de las obras e instalaciones del centro, así como al mantenimiento de los servicios de urbanización. Si bien los primeros lo harán mediante cuotas periódicas cuya recaudación corresponderá a la entidad a la que esté confiada la dirección y gestión del centro, los segundos lo harán de conformidad con lo se establezca en los respectivos títulos concesionales.

En cualquier caso, dichos pagos se efectuarán mediante cuotas periódicas que se exigirán de acuerdo con lo dispuesto en la legislación aplicable, y según los coeficientes de participación previstos para cada una de dichas parcelas y espacios en función de su uso e intensidad.

La ley señala expresamente que la falta de pago de estas cuotas permitirá a la entidad titular del centro acudir a la vía de apremio. 
Otras de las obligaciones que se imponen a los propietarios de las parcelas incluidas en estos centros es, además de cumplir con las determinaciones establecidas en el planeamiento urbanístico, la de solicitar a la entidad gestora del centro, con carácter previo al inicio de su actividad y, por lo tanto, a la solicitud de las correspondientes autorizaciones y licencias, un informe favorable sobre la procedencia de la misma.

Este informe, que se entenderá favorable si no se emite en el plazo de dos meses desde su petición, será requisito imprescindible para la concesión de licencias por las entidades y órganos competentes.

En lo que se refiere a la titularidad dirección y gestión de los centros de transporte de mercancías de interés autonómico, el artículo 22 establece que el ejercicio de estas funciones corresponderá a la Administración autonómica que las desarrollará a través de la entidad a que se refiere la Disposición Adicional Segunda de la ley, es decir, la Empresa Pública de Puertos de Andalucía, en la actualidad Agencia Pública de Puertos de Andalucía, de acuerdo con lo establecido en la Disposición Adicional Primera de la Ley 21/ 2007 de 18 de diciembre, de Régimen Jurídico y Económico de los Puertos de Andalucía.

En efecto, la Disposición Adicional Segunda de la ley dispone que "Sin perjuicio de las competen cias que correspondan directamente a la Administración de la Comunidad Autón oma de Andalu cía, que se reservará, en todo caso, las competencias de planificación, aprobación superior y de dirección y control superior en relación con las áreas de transporte de mercancías, la Empresa Pública de Puertos de Andalucía desarrollará, en cumplimiento desu objeto ampliado, y en los términ os que sefijen en sus Estatutos, las tareas técnicas, económicas y administrativas que se le en comien den en orden a la planificación, fomento, desarrollo y control de la red regional de áreas de transporte de mercancías y, especialmente, la gestión de los cen tros de transporte de mercancías de interés au ton ómico"

Asimismo, la ley establece que la Agencia Pública de Puertos de Andalucía podrá llevar a cabo el ejercicio de estas funciones de dos formas:

a) Directamente, bien por sí misma o a través de sociedades mercantiles de ella dependientes.

La gestión directa a través de sociedades mercantiles ha sido la fórmula utilizada en los centros de transporte de mercancías de interés autonómico "El Higuerón" de Córdoba, "La N egrilla" de Sevilla, así como para la Zona de Actividades Logísticas del Campo de Gibraltar, 
en los que la gestión de los mismos se ha encomendado a sociedades anónimas con participación mayoritaria de la Junta de Andalucía.

b) Indirectamente, mediante el instrumento de la concesión y demás técnicas previstas en la legislación aplicable.

La Ley 5/ 2001 permite la participación de otras administraciones o entidades públicas y privadas en la promoción y gestión de estos centros de transportes de mercancías, en cuyo caso se actuará a través de fórmulas consorciales o asociativas de carácter público o privado, de conformidad con lo dispuesto en las normas reguladoras del sector público de la Comunidad Autónoma y demás legislación aplicable.

Concretamente el consorcio, con el alcance dispuesto en el artículo 6 de la Ley 30/ 1992, ha sido la fórmula utilizada para la promoción y gestión del Centro de Transportes de Mercancías de "T révenez", en Málaga.

El último apartado de este artículo se refiere a los terrenos dotacionales incluidos en los centros de transporte de interés autonómico estableciendo que los mismos estarán adscritos a la Agencia Pública de Puertos de Andalucía que podrá ceder su uso a las entidades mercantiles dependientes de ella y a sus concesionarias.

La cesión del suelo dotacional a las sociedades gestoras de dichos centros ha sido la técnica empleada en el CTM "EI Higuerón", de Córdoba, cuya gestión corresponde a la entidad "Parque Logístico de Córdoba S.A." participada por la Agencia Pública de Puertos de Andalucía y el Ayuntamiento de Córdoba a través de su entidad instrumental, "Proyectos de Córdoba Siglo XXI, S.A."

Tratándose de consorcios, la adscripción a estos centros de las áreas dotacionales en ellos incluidas podrá realizarse en los términos previstos en el convenio correspondiente.

\section{PLANIFICACIÓN TERRITORIAL: LEY 1/ 1994, DE 11 DE ENERO DE ORDENACIÓN DEL TERRITORIO DE ANDALUCÍA}

\section{IV.1.Instrumentos de planificación territorial}

El artículo 5 de la Ley 5/ 2001, incardinado dentro del Título Preliminar de la ley bajo la rúbrica "Disposiciones Generales", establece en su apartado 
primero que "En orden a asegurar la mayor coherencia de la actuación de las Administraciones públicas y de las Entidades pú blicas y privadas implicadas en el transporte de mercancías, los instrumentos de planificación territorial establecidos en la Ley 1/1994, de 11 de enero, de Ordenación del Territorio de la Comunidad Autónoma de Andalucía, servirán como marco de referencia para el establecimiento de las áreas de transporte de mercancías reguladas en la presente Ley"

Por su parte, el Título II de la ley relativo a la "Planificación Territorial y Desarrollo U rbanístico de las Áreas de Transporte de Mercancías", dedica el Capítulo I a la Planificación Territorial y U rbanística de los centros de transporte.

El artículo 15 de dicho capítulo se refiere a los instrumentos de planificación territorial al disponer que "La planificación de las áreas de transporte de mercancías se conten drá en los planes de ordenación del territorio y en los planes sectoriales de transporte que ten gan la consideración de planes con incidencia en la ordenación del territorio, conforme a lo establecido en la Ley 1/1994, de 11 de en ero, de Ordenación del Territorio de la Comunidad Autónoma de Andalucía, los cuales establecerán un marco de referencia espacial para la programación de la actuación de todas las Administraciones Públicas y Entidades públicas y privadas implicadas en el transporte de mercancías"

En virtud de lo anterior, los instrumentos de ordenación territorial que resultan de aplicación son los siguientes:

- Plan de ordenación del territorio de Andalucía, aprobado mediante Decreto 206/ 2006, de 28 de noviembre, por el que se adapta el Plan de Ordenación del Territorio de Andalucía a las Resoluciones aprobadas por el Parlamento de Andalucía en sesión celebrada los días 25 y 26 de octubre de 2006.

Este Plan establece los elementos básicos para la organización y estructura del territorio de la comunidad, configurándose como marco de referencia para los demás planes e instrumentos de ordenación territorial, así como para las actuaciones con incidencia en la ordenación del territorio, tal y como resulta del artículo 6 de la Ley 1/ 1994. Además, ha de tener en cuenta las políticas tanto de la Unión Europea como del Estado que puedan afectar en sus aspectos territoriales a la Comunidad Autónoma.

- Planes de ordenación del territorio de ámbito subregional: Regulados en los artículos 10 a 12 de la Ley 1/ 1994, estos planes establecen los elementos básicos para la organización y estructura del territorio 
en su ámbito, siendo el marco de referencia territorial para el desarrollo y coordinación de las políticas, planes, programas y proyectos de las Administraciones y Entidades públicas así como para las actividades de los particulares.

- Planes con incidencia en la ordenación del territorio: Contemplados en los artículos 17 a 19 de la ley, son aquellos instrumentos que recogen las actividades de planificación de la Junta de Andalucía incluidas en el anexo entre las que se encuentra la planificación regional de los centros de transporte de mercancías y de centros de actividades logísticas del transporte (apartado I.5 del citado anexo).

En este sentido, tanto el Plan Director de Infraestructuras de Andalucía aprobado mediante Decreto 140/ 2006 como el Plan de Infraestructuras para la Sostenibilidad del Transporte en Andalucía 2007-2013 aprobado por Decreto 151/ 2007, tienen esta consideración.

Respecto de las actuaciones con incidencia en la ordenación del territorio, el artículo 30 de la ley dispone que se trata de aquéllas actividades de intervención singular relacionadas en su anexo que se efectúan en ausencia de los planes previstos en la citada ley o que no están contempladas en los mismos. En este sentido, el apartado II relativo a las Actividades de Intervención singular se refiere en su número 3, a los centros de transporte de mercancías y a los centros de actividades logísticas de transporte.

\section{IV.2. Actuaciones de interés autonómico: Efectos}

Como ya se ha visto anteriormente, el artículo 9 de la Ley 5/ 2001 distingue entre los centros de transporte de interés autonómico y local, estableciendo los criterios en base a los cuales un centro de transportes podrá ser objeto de esta declaración.

EI Título IV de la Ley 1/ 1994 de Ordenación del Territorio de Andalucía bajo la rúbrica "De las Actuaciones de Interés Au tonómico" dedica el artículo 38 de la misma a la Declaración de interés autonómico y a sus efectos. Dicho artículo, junto con el artículo 39 relativo a los Planes de Actuación, fue introducido por la Ley $3 / 2004$ de 28 de diciembre de Medidas Tributarias, Administrativas y Financieras.

Así, el apartado primero del artículo 38 establece que "El Consejo de Gobierno podrá declarar de Interés Autonómico, por su especial relevancia derivada de su magnitud, su proyección económica y social o su importancia para la estructuración te 
rritorial de Andalucía, las actuacion es de carácter pú blico con templadas en planes de ordenación del territorio y en planes con incidencia territorial. A simismo podrán ser obje to de esta declaración las actuaciones relativas a los ámbitos sectoriales citados en el Ane xo II de la presente L ey. Esta declaración afectará y comprenderá las obras de titularidad pública a las que las actuaciones anteriores se refieran"

Por lo tanto, y de acuerdo con lo anterior:

- Corresponde exclusivamente al Consejo de Gobierno realizar la declaración de interés autonómico, de acuerdo con el procedimiento previsto en el apartado segundo del mismo artículo. No obstante, tratándose de los Planes Funcionales de los centros de transporte de mercancías de interés autonómico, es la Consejería de Obras Públicas y Transportes el órgano competente para la aprobación.

- Dos son las actuaciones que podrán ser objeto de esta declaración:

- Las actuaciones de carácter público previstas en los planes de ordenación del territorio y en los planes con incidencia territorial, por los motivos de relevancia previstos.

- Las actuaciones relativas a los ámbitos sectoriales citados en el anexo II de la ley entre las que se encuentran, como ya se ha visto, los centros de transporte de mercancías y los centros de actividades logísticas del transporte.

- Por otro lado, la declaración de interés autonómico únicamente afectará a las obras promovidas por la Administración Pública y, en ningún caso, a las promovidas por los particulares.

El procedimiento previsto para esta declaración de interés autonómico es el siguiente:

- En primer lugar, la declaración de interés autonómico se realizará a propuesta de la Consejería competente en materia de ordenación del territorio y urbanismo a iniciativa de la Consejería competente por razón de la actuación.

- La declaración requerirá del trámite de previa audiencia de las Administraciones Públicas afectadas y del Ayuntamiento o Ayuntamientos en cuyo término municipal se ubique la actuación.

- La declaración se producirá una vez redactado el estudio informativo, anteproyecto u otro documento de análogo alcance, a los que se 
acompañará, a los efectos de lo previsto en este artículo, justificación del cumplimiento de los criterios establecidos en el apartado primero del artículo 38.

Asimismo, se prevé que en el acuerdo de declaración de interés autonómico, el Consejo de Gobierno podrá adoptar cuantas medidas se precisen para la construcción y explotación de las obras de titularidad pública por la Administración de la Junta de Andalucía o, en su caso, mediante la intervención de sus empresas públicas.

Especial trascendencia, en cuanto al tema que nos ocupa, adquiere el párrafo quinto del apartado segundo de este artículo 38, al disponer que "L o pre visto en este apartado y en el an terior no se a plicará en aquellos su pu estos en los que la legislación sectorial de aplicación contenga normas específicas sobrela declaración de interés autonómico de determinadas obras de titularidad pública, así como en aquellos casos en los que la declaración esté prevista con tal carácter en los planes de ordenación de territorio 0 en los planes con incidencia territorial"

Por lo tanto y en los supuestos descritos en el párrafo anterior, no será necesaria que la declaración de interés autonómico se realice por el Consejo de Gobierno.

En este sentido, el artículo 12 de la Ley 5/ 2001 regula el procedimiento para la promoción y establecimiento de los centros de transporte de mercancías de interés autonómico, atribuyendo a la Consejería competente en materia de transportes, además de la competencia para su promoción y establecimiento, la competencia para la aprobación del Plan Funcional.

Asimismo, la Disposición adicional primera contiene una relación de los centros de transporte de mercancías declarados de interés autonómico en los siguientes términos:

"Se declaran como cen tros de tran sporte de mercan cías dein terés autonómico el centro de La Negrilla, en el término municipal de Sevilla, gestionado a través de la empre sa pública de la Junta de Andalucía Centro deT ransportedeM ercancías de Sevilla, SA; el cen tro de Trévenez, en el término municipal de Málaga, gestionado por el consorcio Centro de T ransporte de M ercancías de M álaga, y el centro del Campo de Gibraltar, una vez se constituya su entidad de promoción y gestión."

No obstante, esta declaración aparecía condicionada a que en el plazo de seis meses a partir de la entrada en vigor de esta Ley, la entonces Empresa Pú- 
blica de Puertos de Andalucía, con la colaboración de las entidades rectoras y/ o promotoras de los centros de transporte de mercancías señalados anteriormente, presentaran ante la Consejería de O bras Públicas y Transportes, a los efectos de su declaración como centros de transporte de mercancías de interés autonómico, los Planes Funcionales respectivos, con el contenido previsto en el artículo 12 de la Ley 5/ 2001 a fin de que mediante Orden se procediera a su aprobación.

En cuanto al centro del Campo de Gibraltar, con fecha de 28 de julio de 2004 se constituyó la entidad "ZAL del Campo de Gibraltar S.A.", actualmente denominada "ZAL Bahía de Algeciras S.A." como entidad encargada de la promoción y gestión del centro.

Asimismo, la Disposición adicional quinta de la Ley1/ 2007, de 18 de diciembre, de Régimen Jurídico y Económico de los Puertos de Andalucía declara de interés autonómico el proyecto de desarrollo de actividades logísticas, empresariales, industriales tecnológicas y científicas (ALETAS) en la reserva de terrenos delimitada en la zona de Las Aletas, de la Bahía de Cádiz, estableciendo que tendrá la consideración de sistema general de interés supramunicipal.

Que una determinada actuación sea declarada de interés autonómico, tiene especial trascendencia, en la medida en la que le son aplicables los efectos descritos en el apartado tercero del artículo 38 de la Ley de Ordenación del Territorio. De acuerdo con este apartado, "L a aprobación por la Administración de la Junta de Andalucía de los estudios, proyectos y planes relativos a las actuaciones objeto de la declaración de Interés Autonómico, ten drá, de acuerdo con su alcance concreto, los siguientes efectos, además de los que pudiera prever la legislación sectorial de aplicación:

a) Llevará implícita la declaración de la utilidad pública y la necesidad de urgente ocupación a los efectos de la expropiación forzosa de los bienes y derechos necesarios para su ejecución.

b) Legitimará inmediatamente su ejecución siendo sus determinaciones directamente aplicables.

c) Sus determinaciones vincularán directamente al planeamiento del municipio o municipios afectados que, sin perjuicio de lo dispuesto en la letra b) anterior, deberán incorporar dichas determinaciones con ocasión de la siguiente innovación urbanística. 
d) Dado el excepcional interés público que conlleva la declaración de Interés A utonómico, su construcción y puesta en funcionamien to no estarán sujetas a licencias ni, en general, a actos de control preventivo municipal, y ello sin perjuicio del procedimiento de armonización a que hace referencia el apartado 3 del artículo 170 de la Ley 7/2002 de O rdenación U rbanística de Andalucía o el que prevea la legislación sectorial aplicable"

En relación con lo dispuesto anteriormente, cuando el apartado tercero se refiere a la aprobación por parte de los órganos de la Administración autonómica que resulten competentes, de los estudios, proyectos y planes relativos a actuaciones objeto de declaración de interés autonómico, dentro del concepto de plan han de incluirse a los denominados por la Ley 5/ 2001 Planes Funcionales. Estos planes, que serán objeto de desarrollo en el epígrafe $\mathrm{VI}$, son los instrumentos de planificación sectorial necesarios para la implantación de los centros de transporte de mercancías de interés autonómico y contenido se detalla en el artículo 12 de la ley.

Por lo tanto, la aprobación de los Planes Funcionales para la implantación de un centro de transportes de mercancías de interés autonómico por el órgano competente, es decir, la Consejería de O bras Públicas y Transportes de la Junta de Andalucía, supone la atribución de los efectos descritos en las letras anteriores, todo ello sin perjuicio, tal y como dispone la propia ley, de los efectos que pueda establecer la Ley 5/ 2001.

\section{IV.3. Incidencia de las áreas de transporte de mercancías en la ordenación del territorio y medio ambiente}

La Exposición de Motivos de la Ley 5/ 2001, se remite a sus Disposiciones adicionales tercera y cuarta respecto de las posibles incidencias sobre la ordenación del territorio y el medio ambiente de los centros de transportes de mercancías, articulando su establecimiento con los procedimientos específicos previstos, respectivamente, en la Ley 1/ 1994 de Ordenación del Territorio y en la Ley $7 /$ 1994, de 18 de mayo de Protección Ambiental de Andalucía, actualmente derogada y sustituida por la Ley 7/ 2007 de 9 de julio de Gestión Integrada de la Calidad Ambiental.

En relación con los efectos sobre la ordenación del territorio, el artículo 30 de la Ley 1/ 1994 establece, tal y como se ha señalado más arriba, que tendrán la consideración de actuaciones con incidencia en la ordenación del territorio, las actividades de intervención singular que se relacionan en el anexo, entre las que se encuentran los centros de transporte de mercancías y los 
centros de actividades logísticas del transporte, en ausencia de alguno de los planes previstos en dicha ley o cuando no estén contempladas en los mismos.

Estas actuaciones se someterán a informe del órgano competente en materia de ordenación del territorio, que se pronunciará acerca de la coherencia territorial de la misma, en función de sus efectos sobre la ordenación del territorio, estableciendo, en su caso, las medidas correctores, preventivas o compensatorias que deban de adoptarse.

Este informe, que la Ley 1/ 1994 establece con carácter preceptivo, no tiene esta consideración cuando se trata de los centros de transporte de mercancías previstos en el planeamiento urbanístico general, y así lo recoge la Disposición adicional tercera de la Ley 5/ 2001.

Respecto de la incidencia de las áreas de transporte de mercancías sobre el Medio Ambiente, los trámites de prevención habrán de someterse a la citada Ley 7/ 2007 aprobada dentro del marco establecido tanto por la normativa europea como por los distintos instrumentos internacionales que se han articulado en este sentido.

En el plano internacional destaca el Protocolo de Kioto sobre el cambio climático, que tiene por objeto reducir en un porcentaje aproximado del $5 \%$, dentro del periodo que va desde el año 2008 al 2012, en comparación con las emisiones del año 1990, las emisiones de los seis gases generadores del calentamiento global. ${ }^{5}$

En el ámbito de la Unión Europea, la protección del Medio Ambiente constituye un objetivo común de las políticas de transporte y de cohesión a nivel comunitario. Esto supone que en la ejecución de las políticas estructurales de la Unión Europea, el impacto ambiental de los proyectos, incluidos los relativos al sector del transporte, habrá de evaluarse de acuerdo con el principio de desarrollo sostenible y según lo dispuesto en la normativa comunitaria.

En este sentido, la política comunitaria de transportes se ha centrado, entre otras cuestiones, en la promoción de una movilidad sostenible en este sec-

${ }^{5}$ Este instrumento, firmado el 11 de diciembre de 1997, entró en vigor el 16 de febrero de 2005, después de la ratificación por parte de Rusia el 18 de noviembre de 2004. 
tor, de acuerdo con el principio general cohesión al que se ha hecho referencia en diversos Libros Verdes y Blancos de la Comisión Europea. ${ }^{6}$

En efecto, el volumen de tráfico viario tanto de mercancías como de pasajeros, ha aumentado extraordinariamente en los últimos 25 años, lo que ha supuesto, asimismo, un incremento de los niveles de contaminación. Si las emisiones generadas por el tráfico marítimo son comparativamente más bajas que las generadas por otros medios de transporte, la contaminación aérea ha crecido de forma proporcional a su demanda.

Esta circunstancia ha determinado la necesidad de limitar en lo posible el impacto ambiental generado por estos medios de transporte impulsando, a tales efectos, otros modos que sean más respetuosos con el Medio Ambiente, así como favoreciendo la introducción de tecnologías limpias.

En este contexto, la disposición adicional cuarta de la Ley 5/ 2001 señala que "El Anexo segundo de la Ley 7/ 1994, de 18 de mayo, de Protección A mbiental de Andalucía, se amplía en un nuevo supuesto, el número 46, denominado: "Áreas de tran sporte de mercancías, sin perjuicio del sometimiento de las actividades a desarrollar en tales áreas a las medidas de preven ción ambiental de acuerdo con lo previsto en esta Ley".

La Ley 7/ 1994 establecía en su artículo 8 tres medidas de prevención ambiental, la evaluación de impacto ambiental, la calificación ambiental así como el informe ambiental, éste último para las actuaciones relacionadas en su anexo segundo entre las que figuran, como se ha puesto de manifiesto, las áreas de transportes de mercancías.

La promulgación de la Ley 7/ 2007 de 9 de julio de Gestión Ambiental Integrada, deroga, entre otras, la Ley 7/ 1994 de 18 de mayo de Protección Ambiental, el Decreto 292/ 1995 de 12 de diciembre que aprueba el Reglamento

${ }^{6}$ Los Libros Verdes son documentos de reflexión publicados por la Comisión Europea sobre un ámbito político específico que están especialmente destinados a las partes interesadas -organismos y particulares- invitadas a participar en el proceso de consulta y debate y que en algunos casos, pueden conducir a desarrollos legislativos ulteriores. Los Libros Blancos, por su parte, son documentos que contienen propuestas de acción comunitaria en un ámbito específico que pueden ser la continuación de un Libro Verde publicado con el fin de iniciar un proceso de consulta en el ámbito europeo. Mientras que los Libros Verdes exponen un abanico de ideas con fines de debate público, los Libros Blancos contienen un conjunto oficial de propuestas en ámbitos políticos específicos y constituyen la guía para llevarlas a cabo. 
de Evaluación Ambiental, así como el Decreto 153/ 1996 de 30 de abril aprobando el Reglamento de Informe Ambiental, si bien su Disposición Transitoria Segunda dispone que los procedimientos iniciados con anterioridad a la entrada en vigor de la misma para la aprobación, autorización o evaluación ambiental de las actuaciones comprendidas en su ámbito de aplicación, continuarán su tramitación conforme a la normativa que les era de aplicación en el momento de su iniciación, salvo que el interesado solicite su tramitación conforme a lo dispuesto en esa Ley y la situación procedimental del expediente así lo permita.

El artículo 15 de la ley recoge como finalidad de los instrumentos de prevención y control ambiental regulados en la misma, la de prevenir o corregir los efectos negativos sobre el medio ambiente de determinadas actuaciones.

Como instrumentos de prevención ambiental, la ley se refiere en artículo 16 a los siguientes:

a) La autorización ambiental integrada.

b) La autorización ambiental unificada.

c) La evaluación ambiental de planes y programas.

d) La calificación ambiental.

e) Las autorizaciones de control de la contaminación ambiental

Se plantea, en relación con la implantación de los centros de transportes de mercancías, cuál es el instrumento de prevención ambiental que resultaría aplicable, de acuerdo con la nueva ley.

El artículo 19 de la ley establece que, a los efectos de la misma, se entiende por "actuación" los planes y programas, las obras y actividades y sus proyectos regulados en esta Ley y relacionados en el Anexo I de la misma.

En este sentido, el mismo artículo define la autorización ambiental unificada como "La resolución de la Consejería competente en materia de medio ambiente en la que se determina, a los efectos de protección del medio ambiente, la viabilidad de la ejecución y las condiciones en que deben realizarse las actuaciones sometidas a dicha autorización conforme a lo previsto en esta Ley y lo indicado en su Anexo I. En la autorización ambiental unificada se integrarán todas las autorizaciones y pronunciamientos ambientales que correspondan a la Consejería competente en materia de medio ambiente y que sean necesarios con carácter previo a la implantación y puesta en marcha de las actuaciones." 
La regulación pormenorizada de este instrumento de prevención ambiental se contiene en los artículos 27 y siguientes, concretamente, en la Sec-

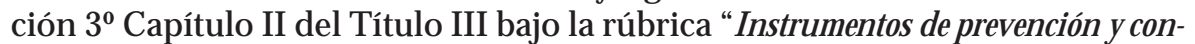
trol ambiental". Dicho artículo establece que se encuentran sometidas a autorización ambiental las actuaciones, tanto públicas como privadas, recogidas en el Anexo I, en las que así se establezca.

Por su parte, el apartado 7.2 del citado anexo sujeta a dicha autorización los proyecto de infraestructuras que tienen por objeto, entre otros, "la construcción de líneas de ferrocarril, lín eas de transportes ferroviarios suburbanos, in stalaciones de transbordo intermodal y de terminales intermodales" mientras que el apartado 7.9 se refiere a "áreas de transporte de mercancías, con la posibilidad, en lo que a este supu esto se refiere, de resolver el procedimien to en el plazo de sés meses"

El artículo 36 de la ley establece en su apartado primero que se encuentran sometidos a evaluación ambiental los planes y programas, así como sus modificaciones, señalados en las categorías 12.1 y 12.2 del Anexo I que cumplan los siguientes requisitos: 1. @ Que se elaboren o aprueben por la Administración de la Junta de Andalucía. 2. Q ue su elaboración y aprobación venga exigida por una disposición legal o reglamentaria o por acuerdo del Consejo de Gobierno.

El apartado 6 del artículo 19 define la evaluación ambiental como el "análisis predictivo destin ado a valorar los efectos di rectos eindirectos sobre el medio a mbiente de aquellas actuaciones sometidas a los procedimientos de preven ción y control ambiental que corresponda en cada caso"

En la categoría 12.1 del citado Anexo, se sujeta a evaluación ambiental los planes y programas que establezcan el marco para la futura autorización de proyectos enumerados en el mismo sobre las siguientes materias: agricultura, ganadería, selvicultura, acuicultura, pesca, energía, industria, minería, transporte, gestión de residuos, gestión de recursos hídricos, ocupación del dominio público marítimo-terrestre, telecomunicaciones, turismo, ordenación del territorio urbano y rural, o del uso del suelo.

Del mismo modo, el artículo de la Ley 9/ 2006, de 28 abril, sobre evaluación de efectos de determinados planes y programas de medio ambiente señala que, a los efectos de la ley, se entenderá por planes y programas el conjunto de estrategias, directrices y propuestas que prevé una Administración pública para satisfacer necesidades sociales, no ejecutables directamente, sino a través de su desarrollo por medio de un conjunto de proyectos, definición que no encaja en el concepto de Plan Funcional de la Ley 5/ 2001. 
De acuerdo con lo anterior, y según el contenido de la citada Ley 5/ 2001, el Plan Funcional es, fundamentalmente, un plan de utilización de los espacios que integra que no alcanza a tener el grado de detalle suficiente que permitiría su consideración como proyecto de infraestructura, según lo dispuesto en el apartado 7 del Anexo I de la Ley, o como un plan o programa de los previstos en el apartado 12, todo ello sin perjuicio del posible sometimiento a los instrumentos de Prevención y Control Ambiental de la Ley 7/ 2007 de los proyectos que lo desarrollen si se encuentran comprendidos en su ámbito de aplicación.

Cuestión diferente es la tramitación ambiental de los Planes Especiales y de los denominados proyectos de ejecución en el ámbito de las áreas de transportes de mercancías. En este sentido, serán estos instrumentos los que deberán de someterse a la tramitación ambiental que en cada caso sea pertinente.

Así, en el caso de los Planes Especiales sobre suelo no urbanizable previstos en la categoría 12.5 de la Ley $7 / 2007$, éstos habrán de someterse a evaluación ambiental, mientras que los proyectos de ejecución correspondientes a las categorías 7.2 y 7.9 del Anexo I antes citado, se sujetarán a autorización ambiental unificada.

\section{PLANIFICACIÓN URBANÍSTICA}

\section{V.1. Instrumentos de planificación urbanística}

El Plan General de Ordenación Urbana, también denominado Plan General, constituye la pieza esencial del ordenamiento urbanístico, siendo el instrumento de ordenación general e integral del territorio de un municipio, en cuyo caso se trata de un plan general municipal de ordenación, o de varios, recibiendo entonces diversas denominaciones como la de plan general plurimunicipal, comarcal o intermunicipal.

En los casos en los que existan instrumentos de ordenación territorial establecidos por la legislación estatal o de las Comunidades Autónomas, las previsiones del Plan General de Ordenación U rbana deberán de respetar las directrices y determinaciones de los mismos, dada su superioridad jerárquica. A su vez, se tendrán en cuenta las previsiones de la planificación sectorial con incidencia en la ordenación del territorio afectado.

En este sentido, el artículo 8 de la LOUA dispone que "Los Planes Generales de Ordenación Urbanística establecen, en el marco de los Planes de Ordenación del 
Territorio, la ordenación urbanística en la totalidad del término municipal y organizan la gestión de su ejecución, de acuerdo a las características del municipio y los procesos de ocupación y utilización del suelo actuales y previsibles a medio plazo"

De esta forma, el Plan General se constituye como el prototipo de plan con naturaleza normativa, configurándose así como la pieza esencial del ordenamiento urbanístico.

El artículo 16 de la Ley 5/ 2001 se dedica a la planificación de los centros de transporte de mercancías a través de cuatro apartados, el primero de los cuales dispone que "L a calificación del suelo necesario para el desarrollo de los centros de transporte de mercancías se establecerá en el planeamiento urbanístico gen eral mediante su previsión específica. En defecto de dicha previsión, los mencionados cen tros también podrán situarse en las zonas en las que, conforme al planeamiento de desarrollo de aquél, esté permitida su implantación"

En relación con lo anterior, es preciso señalar que se entiende por calificación del suelo, la decisión pública, contenida en el Plan, sobre el posible destino urbanístico del territorio mediante la fijación concreta de la clase de uso y destino que corresponde al suelo comprendido en ámbito de aplicación de aquél, mediante la asignación de contenidos o aprovechamientos urbanísticos concretos.

De acuerdo con el artículo 10.1.A.d de la LOUA, forma parte de la ordenación estructural establecida por los Planes Generales de Ordenación U rbana, el establecimiento de los usos, densidades y edificabilidades globales para las distintas zonas del suelo urbano y para los sectores del suelo urbano no consolidado y del suelo urbanizable ordenado y sectorizado.

Supuesto distinto es la calificación pormenorizada del suelo o zonificación, que consiste en la asignación de unas condiciones de uso y edificación a cada una de las zonas resultantes de la ordenación. Esta calificación pormenorizada se diferencia de la calificación global del suelo, en que mientras esta última tiene necesariamente que subdivirse en varios usos en la ordenación detallada (calles, espacios libres, dotaciones, parcelas edificables, etc...) , la calificación pormenorizada es indivisible con posterioridad.

Por lo tanto, corresponde al planeamiento urbanístico general efectuar la calificación global del suelo, pudiendo asimismo establecer una calificación pormenoriza, si bien esta última corresponde efectuarla, generalmente, al planeamiento de desarrollo. En este sentido ha de entenderse la remisión contenida en el párrafo segundo del apartado primero del artículo 16. 
De acuerdo con el apartado segundo del artículo anterior, la tramitación y aprobación de los instrumentos de planeamiento que establezcan las previsiones relativas a los centros de transporte de mercancías se tramitarán y aprobarán conforme a lo previsto en la legislación urbanística, es decir, de acuerdo con las disposiciones establecidas con carácter general en la LOUA (Sección tercera Capítulo IV del Título I), sin que las determinaciones relativas a estos centros supongan el establecimiento de especialidades procedimentales.

No obstante, cuando la implantación del centro de transporte se desarrollara en varios términos municipales, la formulación del planeamiento preciso corresponde, como no podía ser de otro modo, a las entidades supramunicipales que asuman la iniciativa para su establecimiento.

Así, cuando se trate de centros de transporte de mercancías de interés autonómico, la formulación del planeamiento corresponderá a la Consejería de O bras Públicas y Transportes de la Junta de Andalucía, con carácter exclusivo, por ser la competente para su promoción y establecimiento, según el artículo 12 de la Ley 5/2001. Por el contrario, en los centros de transporte de mercancías de interés local que tengan carácter supramunicipal, será competente la entidad local de ámbito superior al municipio que lo promueva o entidad de carácter asociativo constituida al efecto, sin perjuicio de la iniciativa de la Administración autonómica a que se refiere el apartado 2 del artículo 14 sobre cooperación en materia de estaciones y centros de transporte de interés local.

El apartado tercero del artículo 16 hace referencia a los estándares mínimos que habrán de recoger los instrumentos de planeamiento urbanístico para los centros de transporte de mercancías. Así, establece que el planeamiento aplicable deberá prever una reserva mínima, excluidos viarios, equivalente al $10 \%$ de la superficie de su ámbito para espacios libres, y otra de un $15 \%$ de la superficie del mismo para suelo público de carácter dotacional, en orden a la implantación de los servicios señalados en el artículo 8.3 de la Ley, destinados a las empresas y usuarios del sector del transporte.

No obstante, tratándose de suelo urbano, la reserva dotacional mínima del $15 \%$ que se establece con carácter general para todos los centros de transporte de mercancías, podrá reducirse, cuando así se establezca justificadamente en el planeamiento urbanístico, que habrá de tener en cuenta las determinaciones establecidas a tales efectos en el correspondiente Plan Funcional. 
La excepción que el artículo 16.3 prevé en relación con las reservas mínimas previstas con carácter general en la LOUA encuentra cobertura en la Disposición Adicional Cuarta de dicho cuerpo legal al disponer que $L$ as reservas para las dotaciones que en la presente Ley se contemplan no serán de aplicación a lo establecido en la Ley 5/2001, de 4 de junio, de Áreas de T ransporte de M ercancías en la Comunidad Autón oma de Andalucía.

Respecto de las estaciones de mercancías, la ley dispone en el artículo 17 que las mismas podrán calificarse tanto por los instrumentos de planeamiento general municipal como por sus instrumentos de desarrollo, como dotaciones de transporte y comunicaciones con carácter de sistemas generales o locales, dependiendo de su importancia y de la función que desarrollen.

\section{V.2. Supramunicipalidad, declaración de interés autonómico: efectos}

Como ya señalábamos anteriormente, la aprobación por la Administración de la Junta de Andalucía de los estudios, proyectos y planes relativos a las actuaciones objeto de la declaración de interés autonómico, conlleva la producción de efectos específicos inherentes a su especial relevancia pública.

Entre tales efectos, resulta de especial relevancia el establecido en la letra d) del artículo 38 que dispone que "Dado el excepcional interés público que conlle va la declaración de Interés Autonómico, su construcción y puesta en funcionamiento no estarán sujetas a licen cias ni, en gen eral, a actos de control preventivo municipal, y ello sin perjuicio del procedimiento de armonización a que hace referen cia el apartado 3 del artículo 170 de la L ey 7/2002 de Ordenación U rbanística de Andalucía o el que prevea la legislación sectorial aplicable" 7 .

En lo que a los centros de transporte de mercancías se refiere, la aprobación por la Administración Autonómica de los Planes Funcionales, como instrumentos de planificación sectorial de los centros de transporte de mercancías, actuaciones susceptibles de esta declaración de acuerdo con lo previsto en el anexo de la Ley 1/ 1994, supone una excepción a la no aplicación de lo

${ }^{7}$ La licencia se constituye, según Parada, como una autorización municipal de carácter reglado que, sin perjuicio de tercero, permite la ejecución de obras o la utilización del suelo que los instrumentos urbanísticos han previsto en cada terreno Se trata, por tanto, de una técnica administrativa basada en el control de los actos de edificación y otros usos del suelo, para garantizar su adecuación y sometimiento tanto a la legalidad como al planeamiento urbanístico. 
dispuesto en el artículo 169 de la LO U A que establece, por una parte, la sujeción a previa licencia urbanística municipal, sin perjuicio de las demás autorizaciones o informes que sean procedentes con arreglo a esta Ley o a la legislación sectorial aplicable, de los actos de construcción o edificación e instalación y de uso del suelo, incluidos el subsuelo y el vuelo y, por otra parte, los actos de construcción, edificación y uso del suelo o del subsuelo que realicen los particulares en terrenos de dominio público, sin perjuicio de las autorizaciones o concesiones que deba otorgar la Administración titular de dicho dominio.

También están sujetos a licencia, de acuerdo con el apartado primero del artículo 170, los actos descritos en el artículo 169 cuando sean promovidos por una Administración Pública o por cualquiera de sus entidades adscritas o dependientes distintas de la municipal, salvo que se trate de los actos de ejecución, realización o desarrollo de las obras, instalaciones o usos a que se refiere el apartado segundo, así como en los supuestos en los que se trate de actos promovidos por una Administración Pública en los que concurra un excepcional o urgente interés público. La Administración promotora del proyecto técnico deberá, para legitimar la misma, acordar su remisión al municipio correspondiente para que, en el plazo de un mes, comunique a aquélla la conformidad o disconformidad del mismo con el instrumento de planeamiento de aplicación.

En los casos en los que estos actos sean promovidos por la Administración de la Comunidad Autónoma de Andalucía o entidades adscritas o dependientes de la misma, en caso de comunicación de la disconformidad, las actuaciones deberán ser remitidas a la Consejería competente en materia de urbanismo para que, tras los informes correspondientes y junto con su propuesta, las eleve al Consejo de Gobierno, que decidirá sobre la procedencia de la ejecución del proyecto. El acuerdo que estime dicha procedencia, que posibilitará su inmediata ejecución, deberá ordenar la iniciación del procedimiento de innovación del instrumento de planeamiento. Este es el procedimiento de armonización a que se refiere el último inciso de la letra d) del apartado tercero del articulo 38 de la LOT antes citado.

Por tanto, para que el establecimiento de un centro de transporte de mercancías esté exento de licencia o de cualquier otro instrumento de control preventivo municipal, se requiere que dicha actuación haya sido declarada de interés autonómico por la Consejería de O bras Públicas y Transportes mediante el procedimiento descrito en la Ley 5/ 2001. 


\section{PLANIFICACIÓN FUNCIONAL}

\section{VI.1. Plan Funcional: Concepto y contenido}

El Plan Funcional regulado en la Ley 5/ 2001 es un instrumento de planificación sectorial cuyo objeto es la determinación de los elementos que condicionan la ordenación, explotación e integración en el territorio de los centros de transporte de mercancías, configurándose así como el elemento fundamental para su desarrollo, al contener los aspectos esenciales que regirán su configuración y funcionamiento.

El artículo 12 de la ley recoge, por una parte, el contenido mínimo del Plan Funcional, así como el procedimiento para su aprobación. De acuerdo con lo anterior, el Plan Funcional habrá de recoger necesariamente las siguientes determinaciones:

- La evaluación de la repercusión de su localización en orden al desarrollo regional y local.

- La determinación del ámbito territorial de su implantación.

- El plan de utilización de los espacios que integra, distinguiendo los espacios de dominio público de carácter dotacional destinados a acoger actividades prestacionales y de servicios a las empresas del sector del transporte de aquellas otras zonas destinadas al desarrollo de otras actividades cuya promoción, disposición y explotación se hayan de regir por el Derecho privado.

- Las fórmulas de cooperación e integración de otras Administraciones y de la iniciativa privada en orden a la promoción, construcción y gestión del centro.

- El programa y estudio económico-financiero para su promoción, construcción y explotación.

- Aquellas otras determinaciones que se establezcan reglamentariamente para lograr asegurar y contrastar la viabilidad del centro, definir las funciones, estructura empresarial y objetivos de su actuación, y alcanzar su mejor integración en la ordenación urbanística y territorial del lugar de su implantación.

Respecto del procedimiento para la elaboración y aprobación:

- La elaboración del Plan Funcional corresponde a la entidad que asuma la iniciativa.

- Con carácter previo a su aprobación, el Plan Funcional se someterá a información pública y a audiencia de los Ayuntamientos y de otras 
Administraciones, entidades públicas y agentes sociales afectados por un plazo no inferior a un mes.

En el supuesto de que el centro de transporte de mercancías no estuviera previsto en los planes de ordenación del territorio o de ordenación urbana, la entidad que asuma la iniciativa habrá de someter el proyecto de Plan Funcional del centro, con anterioridad a su sometimiento a información pública, a informe del órgano competente en materia de ordenación del territorio, de acuerdo con las previsiones establecidas a este respecto en el artículo 30 de la Ley 1/ 1994 de Ordenación del Territorio. ${ }^{8}$

- Completada la fase de información pública y de audiencia, el órgano que hubiera acordado la apertura de dicha fase incorporará, en su caso, al proyecto del Plan Funcional del centro las modificaciones que resultaren necesarias como consecuencia de las alegaciones e informes producidos durante aquélla, y lo remitirá con todo lo actuado a la Consejería competente en materia de transportes.

- La aprobación definitiva del establecimiento de los centros de transporte de mercancías de interés local y autonómico y de su Plan Funcional corresponde a la Consejería competente en materia de transportes. De no recaer resolución expresa, en el plazo de seis meses, el silencio administrativo se entenderá desestimatorio.

La ley contempla igualmente el procedimiento a seguir en los supuestos de modificación de los Planes Funcionales señalando que, en estos casos, la aprobación corresponde, lo mismo que para su aprobación, a la Consejería competente en materia de transportes, por el mismo procedimiento establecido para su aprobación.

\section{${ }^{8}$ Artículo 30.}

1. Las actividades de intervención singular que se relacionan en el anexo, y que se efectúen en ausencia de plan de los previstos en esta Ley o no estén contempladas en los mismos, tendrán a efectos de esta Ley la consideración de Actuaciones con Incidencia en la Ordenación del Territorio y se someterán a informe del órgano competente en Ordenación del Territorio.

2. El informe a que hace referencia el apartado anterior versará sobre la coherencia territorial de la actuación en virtud de sus efectos en la O rdenación del Territorio y señalará, en su caso, las medidas correctoras, preventivas o compensatorias que deban adoptarse.

3. El plazo para la emisión del informe será de dos meses a partir de la recepción de la documentación a que se refiere el artículo 31, transcurrido el cual sin pronunciamiento expreso se considerará que el mismo tiene carácter favorable. 
Por otra parte, la ampliación de los centros de transporte se llevará a cabo mediante la modificación de sus Planes Funcionales, independientemente de si la ampliación se lleva a cabo por extensión del recinto existente sobre espacios contiguos, o por el desarrollo de otras zonas complementarias sitas en el área territorial a la que sirven, siempre que se mantenga la dirección y gestión conjunta del centro ampliado.

Este mismo procedimiento se seguirá en los supuestos en los que un centro de transportes de mercancías de interés local concurran las circunstancias previstas en el artículo 9.2 para ser considerados de interés autonómico, en cuyo caso la Consejería competente en materia de transportes formulará un nuevo Plan Funcional del centro para su declaración como de interés autonómico, previo acuerdo con la Administración o entidad titular del mismo sobre las condiciones de toda índole derivadas de su transformación.

\section{VI.2. Plan Funcional como proyecto de actuación}

O tra de las cuestiones planteadas en el marco del artículo 39 de la Ley 1/ 1994 de Ordenación del Territorio es la consideración del Plan Funcional como proyecto de actuación a los efectos previstos en dicho artículo y en el artículo 38 de la citada ley.

En efecto, el párrafo tercero del apartado segundo del artículo 39 establece que "Podrá considerarse proyecto de actuación a los efectos de este artículo y el anterior, cualquier documento previsto, con análogo alcance, en la legislación sectorial aplicable a la actuación de que se trate".

El apartado primero de ese artículo señala que "Cuando las actuaciones a que se refiere el artículo 38 supongan la implantación de usos productivos, dotaciones, o cualesquiera otros análogos que precisen desarrollo urbanístico, la declaración de Interés Autonómico se producirá mediante la aprobación por el Consejo de Gobierno de un proyecto de actuación a propuesta de la Consejería competente en materia de ordenación de territorio y urbanismo, previa iniciativa de la Consejería competente en razón de la actuación".

Este proyecto de actuación habrá de someterse, con carácter previo a su aprobación y por plazo no inferior a dos meses, a audiencia de las Administraciones públicas afectadas; teniendo en todo caso esta consideración el Ayuntamiento o Ayuntamientos del término municipal en que aquél se ubique. 
Asimismo, el proyecto se someterá a información pública por plazo no inferior a un mes, siendo necesario el requerimiento de informes, dictámenes 0 cualquier otro tipo de pronunciamientos de los órganos y entidades administrativas gestoras de los intereses públicos afectados que sean legalmente preceptivos.

En el caso de los Planes Funcionales, su procedimiento de aprobación es análogo al de los proyectos de actuación:

- $\quad$ Han de someterse por un plazo no inferior a un mes a información pública y a audiencia no solo de los Ayuntamientos y de otras Administraciones, sino también de cual esquiera entidades públicas y agentes sociales afectados.

- A los efectos previstos en el artículo 30 de la LOUA, en el supuesto de que el centro de transporte de mercancías no estuviera previsto en los planes de ordenación del territorio o de ordenación urbana, la entidad que asuma la iniciativa habrá de someter el proyecto de Plan Funcional del centro, con anterioridad a su sometimiento a información pública, a informe del órgano competente en materia de ordenación del territorio.

Respecto del contenido de los proyectos de actuación, el artículo 39 deberá justificar la concreta ubicación de la actuación, su incidencia territorial y ambiental, y su grado de integración con la planificación y ordenación vigente; así como asegurar el adecuado funcionamiento de las obras e instalaciones que constituyan su objeto, pudiendo prever la distinción entre espacios de dominio público y otros espacios de titularidad pública o privada.

Por su parte, el Plan Funcional habrá de contemplar necesariamente la evaluación de la repercusión de su localización en orden al desarrollo regional y local; la determinación del ámbito territorial de su implantación; el plan de utilización de los espacios que integra; las fórmulas de cooperación e integración de otras Administraciones y de la iniciativa privada;; el programa y estudio económico-financiero, así como aquellas otras determinaciones que se establezcan reglamentariamente para lograr asegurar y contrastar la viabilidad del centro, definir las funciones, estructura empresarial y objetivos de su actuación, y alcanzar su mejor integración en la ordenación urbanística y territorial del lugar de su implantación.

De esta forma, ambos pretenden una ordenación integral de la actuación a realizar, buscando una ubicación estratégica, procurando su viabilidad ma- 
terial y empresarial y su armónica inserción en el modelo territorial y urbanístico existente.

La equiparación de estos planes y proyectos supone, asimismo, la aplicación de lo dispuesto en el apartado cuarto del artículo 39, de forma que corresponderá, en todo caso, a la Consejería competente en materia de ordenación del territorio y urbanismo la aprobación de todos los instrumentos y documentos que se precisen para el desarrollo y completa ejecución del Plan Funcional, incluidos los proyectos de urbanización que procedieren.

De lo anterior se desprende que la equiparación del Plan Funcional al proyecto de actuación supone que si la aprobación de éste por el órgano competente conlleva la declaración de interés autonómico, idéntico efecto habría de vincularse a la aprobación por el órgano competente, en este caso la Consejería competente en materia de transportes, de un Plan Funcional.

\section{VI.3. Efectos del Plan Funcional sobre la planificación urbanística}

En este punto hemos de remitirnos, una vez más, a lo dispuesto en el artículo 38 de la Ley 1/ 1994 sobre los efectos de la aprobación, por la Administración autonómica, de los estudios, proyectos y planes relativos a las actuaciones objeto de la declaración interés autonómico.

En este sentido, la aprobación por parte de la Consejería competente en materia de transportes de los Planes Funcionales de los centros de transporte de mercancías declarados de interés autonómico, produce los siguientes efectos con incidencia sobre la planificación urbanística:

- Lleva implícita la declaración de utilidad pública y la necesidad de urgente ocupación a los efectos de la expropiación forzosa de los bienes y derechos necesarios para su ejecución.

El efecto descrito en este apartado hay que conectarlo con los que el artículo 73 de la LOUA atribuye a la delimitación de reservas de terrenos al disponer en su apartado quinto que el establecimiento o la delimitación de las reservas de terrenos con la finalidad expresada en los apartados anteriores comporta la declaración de la utilidad pública a efectos de expropiación forzosa por un tiempo máximo de cinco años, prorrogable por una sola vez por otros dos; debiendo iniciarse el expediente expropiatorio en el curso del referido plazo. 
Esta reserva de terrenos, cuando tiene como destino último la implantación de un centro de transporte de mercancías, puede llevarse a cabo mediante la aprobación del correspondiente Plan Especial, en los casos en los que se trata de una actuación a llevar a cabo en suelo no urbanizable y se den los demás requisitos establecidos en la letra b) del apartado tercero del citado artículo, a saber:

$\checkmark$ Que se haga en ausencia de Planes de O rdenación del Territorio, Planes con Incidencia en la Ordenación del Territorio y Plan General de Ordenación U rbanística, o ante la falta de previsión en los mismos de las reservas de terrenos para los patrimonios públicos de suelo.

$\checkmark$ Q ue la delimitación se realice a instancias de la Consejería competente en materia de urbanismo.

- Legitimará inmediatamente su ejecución siendo sus determinaciones directamente aplicables.

- Sus determinaciones vincularán directamente al planeamiento del municipio o municipios afectados que, sin perjuicio del efecto anterior, deberán incorporar dichas determinaciones con ocasión de la siguiente innovación urbanística.

De lo anterior resulta el carácter vinculante del Plan Funcional, como instrumento de planificación sectorial de los centros de transporte de mercancías declarados de interés autonómico con el contenido descrito en el artículo 12 de la Ley 5/ 2001,sobre el instrumento de planificación urbanística del municipio o municipios afectados, procurando así su inserción en el modelo territorial y urbanístico existente.

\section{CENTROS DE MERCANCÍAS EXISTENTES Y PROYECTOS EN DESARROLLO}

En la actualidad, la totalidad de los centros de transporte de mercancías existentes en Andalucía han sido declarados de interés autonómico.

Como ya se ha expuesto en anteriores epígrafes, la Disposición Adicional Primera de la Ley $5 / 2001$ ha declarado de interés autonómico los centros de "La Negrilla", en el término municipal de Sevilla, de "Trévenez", en el término municipal de Málaga, el centro del Campo de Gibraltar, actualmente conocido como la Zona de Actividades Logísticas del Campo de Gibraltar. 
Por otra parte, la Ley 21/ 2007, de 18 diciembre de Régimen Jurídico de los Puertos de Andalucía declara de interés autonómico el proyecto de desarrollo de actividades logísticas, empresariales, industriales, tecnológicas y científicas (ALETAS) en la reserva de terrenos delimitada en la zona de Las Aletas, de la Bahía de Cádiz.

En el caso del Centro de Transportes de Mercancías "El Higuerón" de Córdoba, la declaración de interés autonómico tuvo lugar con la aprobación por parte de la Consejería de O bras Públicas y Transportes de la Junta de Andalucía de su Plan Funcional, mediante Orden de 7 de Junio de 2006 publicada en el número 116 del Boletín O ficial de la Junta de Andalucía de 19 de Junio de 2006.

Este es el procedimiento seguido en la actualidad para la implantación de otros centros de transporte de mercancías de interés autonómico, como los de Linares y Bailén. En relación con estos centros, mediante dos órdenes de 4 de marzo de 2009 (BO JA no 55 de 20 de marzo) del Consejero de Obras Públicas y Transportes de la Junta de Andalucía, se aprobaron sus Planes Funcionales.

Más recientemente, mediante O rden de 6 de marzo de 2009, se ha dado inicio al procedimiento para la promoción y establecimiento del Centro de Transportes de Mercancías de interés autonómico de Antequera (Málaga) que se encuentra en fase de tramitación.

Los instrumentos que desde el punto de vista territorial y urbanístico se han utilizado para la implantación de los principales centros de transporte de mercancías de interés autonómico han sido los siguientes:

\section{CTIM "EI Higuerón" de Córdoba}

El Plan General de Ordenación Urbanística de Córdoba aprobado el 21 de diciembre de 2001, reservó una parcela de 368.104 m2 para la ubicación de un Centro de Transporte Intermodal de Mercancías, clasificando dicho suelo como sistema general adscrito al suelo urbanizable no programado.

En dicho instrumento, se establecía la necesidad de redactar un Plan Especial para la ordenación del citado sistema general, con el objetivo de ejecutar el citado centro de Transporte de Mercancías Intermodal Público y sus servicios complementarios, conectado de modo directo con la Estación de Clasificación de RENFE en EI Higuerón y comunicado con la carretera N-IV a través de la Variante 0 este. 
El Plan General de Ordenación Urbana de Córdoba señalaba en su artículo 10.2.3 la titularidad y gestión pública de los sistemas generales que, una vez obtenidos, se afectarían al uso público o se adscribirían a un servicio público o a otros usos de interés social.

Por su parte, el Plan Especial de desarrollo manifestaba que los terrenos incluidos en el sistema general SG-CTIM se obtendrían por expropiación, que fue llevada a cabo mediante el procedimiento de tasación conjunta, de acuerdo con las determinaciones establecidas en los artículos 162 a 167 de la Ley 7/ 2002 de Ordenación U rbanística de Andalucía.

En cuanto a su Plan Funcional, el mismo fue aprobado mediante Orden de 7 de Junio de 2006.

La gestión de este centro de transportes de mercancías, de acuerdo con lo estipulado en el artículo 22.1 de la Ley 5/ 2001, viene encomendada a la entidad "Parque Logístico de Córdoba S.A" cuyos accionistas, tal y como se adelantó en el epígrafe III , son la empresa municipal "Proyectos de Córdoba siglo XXI S.A." y la Agencia Pública de Puertos de Andalucía.

\section{ZAL del Campo de Gibraltar}

El Plan Director de Infraestructuras de Andalucía prevé en su punto 6.2.2. la implantación en el Campo de Gibraltar de una Zona de Actividades Logísticas.

Por otra parte, como se menciona más arriba, la Disposición Adicional Primera de la Ley 5/ 2001 declaró el mismo de interés autonómico mediante Orden de 16 de mayo de 2006 (BOJA 109, de 8 de junio)

En dicho Plan se estructura la zona en cuatro sectores funcionales, tres en el área de Guadarranque, que se reparte entre los términos municipales de Los Barrios y San Roque, y un cuarto en el área de El Fresno, en el término municipal de Los Barrios.

Para su desarrollo y ejecución, mediante resolución de 19 de octubre de 2006 de la Secretaría General de Ordenación del Territorio y U rbanismo se acordó la formulación del Plan Especial de delimitación de una reserva de terrenos en la Vega de Guadarranque en el término municipal de Los Barrios, en Cádiz, para la implantación del citado centro de transporte de mercancías y que comprende los sectores 3 y 4 del Plan Funcional aprobado. 
Los terrenos objeto de la reserva comprenden unas 180 has integradas por suelos clasificados como no urbanizables en el PGOU de Los Barrios.

Por otra parte, mediante resolución de 17 de noviembre de 2006, se acordó la aprobación definitiva del Plan Especial del sector 002-ES-CTM resultante de la modificación puntual del Plan General de Ordenación U rbanística de San Roque para la implantación de una Zona de Actividades Logísticas.

Respecto del sector El Fresno, con fecha de 5 de marzo de 2004 se aprobó definitivamente el Plan Parcial de Ordenación del sector Fresno Sur asignándole como uso característico el terciario.

En lo que al Plan Funcional de esta zona de actividades logísticas se refiere, el mismo se aprobó mediante Orden de16 de mayo de 2006.

Como ya se apuntó anteriormente, la gestión de esta Zona de Actividades L ogísticas corresponde a la entidad "ZAL Bahía de Algeciras S.A", entidad participada mayoritariamente por la Junta de Andalucía a través de la Agencia Pública de Puertos de Andalucía y de la Agencia de Innovación y Desarrollo de Andalucía.

Área de Actividades Logísticas, Empresariales, Tecnológicas, Ambientales y de servicios de la Bahía de Cádiz “Las Aletas”, en Puerto Real.

Mediante Orden de 13 de octubre de 2005, se acordó la aprobación definitiva del Plan Especial para la delimitación del Área de Reserva de terrenos en la zona de las Las Aletas en Puerto Real para su incorporación al patrimonio autonómico de suelo.

Esta delimitación se aprueba en ejecución de las previsiones del Plan de Ordenación del Territorio de la Bahía de Cádiz a probado por el Consejo de Gobierno mediante Decreto 462/ 2004, de 27 de junio, en el que se crea la referida área de reserva como ZERPLA, Aletas Río San Pedro.

El artículo 3 de la Orden de 23 de julio de 2007 (B0) A no 146 de 25 de julio) por la que se acordó la formulación de dicho Plan Especial, establecía que el mismo contenía, además de las determinaciones propias de este tipo de instrumento conforme a la legislación urbanística, las justificaciones precisas para que fuera considerado documento de análogo alcance al proyecto de actuación, de acuerdo con el artículo 39.2 de la Ley 1/ 1994, de 11 de enero. 
Mediante Orden de 25 de enero de 2008 tuvo lugar la aprobación definitiva del Plan Especial de interés supramunicipal del área de actividades logísticas, empresariales, tecnológicas, ambientales y de servicios en la Bahía de Cádiz "Las Aletas", en Puerto Real, cuyo objeto consiste en la ordenación urbanística de los terrenos comprendidos en el Plan Especial de reserva a que se refiere el párrafo primero de este apartado.

Anteriormente, con fecha de 27 de diciembre de 2007, se publicó en el Boletín O ficial de la Junta de Andalucía la Ley 21/ 2007 de 18 de diciembre de Régimen Jurídico y Económico de los Puertos de Andalucía cuya Disposición Adicional Quinta declara de interés autonómico el Proyecto Aletas.

La anulación mediante sentencia del Tribunal Superior de Justicia de Andalucía de 26 de febrero de 2008, que ha sido recurrida en casación ante el Tribunal Supremo, del Plan Especial de Delimitación de Reserva de Terrenos, abrió la posibilidad de que se generaran determinadas expectativas de derechos que habían de ser tenidas en cuenta en la tramitación de la aprobación del proyecto de actuación.

Por este motivo, se dispuso la incorporación a dicho proyecto de actuación, a efectos de su aprobación por el Consejo de Gobierno, de una relación de bienes y derechosque podían verse afectados por el mismo, así como su sometimiento a un nuevo trámite de información pública, lo que tuvo lugar mediante resolución de 9 de julio de 2008 de la Secretaría general de Planificación y Desarrollo Territorial.

El Consorcio de Actividades Logísticas, Empresariales, Tecnológicas, Ambientales y de Servicios de la Bahía de Cádiz denominado "Consorcio Aletas" y suscrito por la Administración General del Estado y la Junta de Andalucía es el órgano encargado de su gestión.

\section{Centro de Transportes de Mercancías de Trévenez, Málaga}

La implantación de este centro de transportes vino precedida por la declaración de utilidad pública de sus instalaciones efectuada mediante acuerdo del Pleno del Ayuntamiento de Málaga de 31 de julio de 1992, aprobándose definitivamente con fecha de 2 de julio de 1993 un Plan Especial sobre los terrenos afectados, en base al artículo 350 del Plan General de Ordenación U rbana en aquel momento vigente.

Posteriormente, mediante Orden de la Consejería de Vivienda y Ordenación del Territorio de 2 de julio de 2008 (BOJA no 139 de 14 de julio) tuvo lu- 
gar la aprobación definitiva del proyecto de delimitación de reserva de terrenos en la zona de Buenavista, Málaga, para la ampliación en 39,14 H as del citado centro de transportes.

La aprobación de su Plan Funcional se produjo con fecha de 15 de noviembre de 2005 (BOJA no 240 de 12 de diciembre) que, con ocasión de la ampliación a que se refiere el párrafo anterior, fue objeto de modificación mediante orden de 25 de octubre de 2007. En la actualidad, dicho Plan Funcional se encuentra en la fase de información pública y audiencia, de acuerdo con lo establecido en el artículo12 de la Ley 5/ 2004.

La gestión de este centro viene encomendada al Consorcio Centro de Transportes de Mercancías de Málaga suscrito por la Junta de Andalucía y el Ayuntamiento de Málaga.

Centro de Transportes de Mercancías "La Negrilla", Sevilla.

El ámbito espacial del CTM Sevilla comprende los suelos que integraban Ia Parcela B-2 del Plan Especial Ciudad del Transporte PERI-TO-6, aprobado definitivamente en junio de 1988 cuya última modificación data de mayo de 1998, así como la Parcela II del Plan Parcial SU P-TO-1 de Palmete aprobado definitivamente el 8 de abril de 1.995.

EI Plan Funcional de este centro de transportes tuvo lugar mediante Orden de la Consejera de O bras Públicas y Transportes de 20 de agosto de 2004.

Por su parte, el Plan Director de Infraestructuras de Andalucía prevé en su punto 6.2.9 relativo al Área Metropolitana de Sevilla, la necesidad de completar las infraestructuras del sistema de transporte de la zona con el pleno desarrollo del Centro de Transporte de Mercancías ya en funcionamiento y la dotación de otro, situado en Majarabique, sobre la red ferroviaria, entre los términos municipales de Sevilla y La Rinconada (Sevilla)

En el municipio de Sevilla, la Revisión del Plan General de Ordenación U rbanística fue aprobada definitivamente mediante Resolución de la Consejería de O bras Públicas y Transportes de 19 de julio de 2006.

El citado Plan General establecía la necesidad de una reserva para un Sistema General destinado a Centro de Transporte de Mercancías (CTM) con U so Global para actividades productivas y especialización para las logísticas y servicios complementarios sobre terrenos clasificados como suelo urbanizable no sectorizado, SU N S-DM N-01, «Nodo Logístico N orte". 
En cuanto al municipio de La Rinconada su planeamiento general clasificó los terrenos incluidos en el ámbito de la reserva como no urbanizables.

En virtud de lo anterior, con fecha de 13 de abril de 2007 se acordó la formulación del Plan Especial de interés supramunicipal de delimitación de una reserva de terrenos en la zona de "Majarabique" en los términos municipales de Sevilla y la Rinconada (Sevilla) para la ampliación del centro de transportes.

Posteriormente, mediante Orden de 18 de enero de 2008, se modificó el artículo 2 de la orden a que se refiere el párrafo anterior, como consecuencia de la aprobación parcial del PGOU de La Rinconada, que clasificó los terrenos comprendidos en el ámbito de la reserva como suelo urbanizable no sectorizado, SU NS-4"N odo Logístico N orte", por lo que se propuso la ampliación de la extensión de la reserva inicialmente prevista en aproximadamente otras $43 \mathrm{H}$ as pertenecientes a este municipio, quedando establecida en aproximadamente $207 \mathrm{H}$ as la reserva de terrenos delimitada por el citado Plan Especial.

La necesidad de llevar a cabo la ampliación de este centro de transportes, ha dado lugar a la modificación de su Plan Funcional mediante O rden de 25 de octubre de 2007 que, como en el caso de Málaga, se encuentra en la fase de información pública y audiencia.

La gestión de este centro corresponde a la entidad CTMS S.A. de la que es socio único la Agencia Pública de Puertos de Andalucía.

\section{CONCLUSIONES. VALORACIÓN DEL RÉGIMEN NORMATI- VO EXISTENTE EN LA MATERIA:LEY 5/ 2001}

Una vez que han quedado expuestas las líneas fundamentales de la Ley 5/ 2001, conviene hacer una valoración de la misma, tanto desde el punto de vista formal como sustantivo.

En el primero de estos aspectos, una de las cuestiones que más llaman la atención es la parquedad de la ley a la hora de definir su objeto, que circunscribe al concepto de áreas de transportes de mercancías, integradas por los centros y por las estaciones de transporte.

En este sentido, la ley podría haber sido más ambiciosa, recogiendo otros conceptos que definieran con mayor precisión aspectos fundamentales de di- 
chas áreas, como son la intermodalidad y la logística. Dado que no existe un criterio unívoco acerca de qué debe entenderse por parque, zona o plataforma logística, hubiera sido conveniente su inclusión al objeto de mostrar las diferencias entre unos y otras, contribuyendo de esta forma a consolidar conceptos de una materia en desarrollo.

En relación con los Planes Funcionales, sería igualmente útil una regulación que fuera mucho más exhaustiva, de forma que se pusiera de manifiesto de una manera clara y precisa la naturaleza del Plan Funcional, y su distinción respecto de los instrumentos de planificación territorial y urbanística.

Es decir, habría de establecerse una regulación en la que el Plan Funcional se postulara como instrumento de planificación sectorial para la ordenación, explotación e integración en el territorio de los centros de transporte de mercancías, con un ámbito de actuación ceñido exclusivamente a la Ley 5/ 2001 y, por lo tanto, distinto al de los instrumentos de ordenación territorial y urbanístico, ya sean éstos generales o de desarrollo, con un tratamiento jurídico totalmente diferenciado.

Asimismo y en lo relativo a las modificaciones de los Planes Funcionales, apenas apuntada en el apartado 6 del artículo 12, sería conveniente que se distinguiera entre las modificaciones sustantivas y meramente formales, estableciendo distinto régimen jurídico para cada una de ellas.

O tro aspecto que podría haber contemplado la Ley 5/ 2001 es el relativo a los efectos que produce la declaración de interés autonómico de un centro o estación de transporte de mercancías. Aunque en un principio entendemos aplicables los efectos previstos en las letras a) a d) del apartado tercero del artículo 38 de la Ley 1/ 1994 de Ordenación del Territorio, en la práctica la remisión a la normativa territorial suscita posturas encontradas, sobre todo en cuanto a la no sujeción a licencias ni a actos de control preventivo municipal de las actuaciones objeto de interés autonómico.

Por otra parte, debería de haberse contemplado en la ley todo lo relativo a la potestad sancionadora, atribuyendo a la Agencia Pública de Puertos de Andalucía, como entidad encargada de la gestión de dichas áreas, la competencia para el establecimiento de infracciones y sanciones en dicho ámbito.

O tro de los aspectos de la Ley 5/ 2001 que convendría desarrollar es la escueta previsión que sobre el régimen de gastos comunes establece el artículo 21.3. De un lado, porque la referencia a gastos de conservación y de servicios 
resulta insuficiente y, de otro, por la necesidad de establecer el régimen de determinación de cuotas y de recaudación de las mismas.

La materia concesional debiera igualmente tener un régimen específico, estableciendo la especialidad del supuesto de títulos a favor de las sociedades instrumentales previstas en el artículo 22 1.Este tratamiento singular debería incluir la no aplicación del principio de concurrencia, habilitando la adjudicación directa y la posibilidad de establecer exenciones o bonificaciones en la tasa a abonar por la instrumental concesionaria.

Asimismo, debería de establecerse un régimen concesional propio para el resto de los supuestos, en correspondencia con la aplicación preferente de la ley especial, a que se refiere el artículo 82.1 del Decreto 276/ 1987, de 11 noviembre por el que se aprueba el Reglamento de aplicación de Ley 4/ 1986, de Patrimonio de la Comunidad Autónoma de Andalucía.

Tal regulación contendría los aspectos propios de la materia relativos al inicio de expedientes, bien de oficio o a instancias de interesado, trámites para la concurrencia de ofertas y concursos, contenido mínimo de los anteproyectos y proyectos, documentación a acompañar con las propuestas, plazos máximos, régimen tarifario de los concesionarios, transmisiones y derechos de tanteo y retracto entre otros.

Por último, sugerimos asimismo desarrollar un régimen propio de ingresos por explotación, cesión de suelo e instalaciones, y prestación de servicios, distinguiendo los de naturaleza tributaria, tasas y precios públicos inherentes a las concesiones y servicios públicos, y los de carácter privado, relativos a la explotación de bienes patrimoniales y servicios comerciales.

En el primer supuesto se desarrollarían los elementos propios del hecho tributario, hecho imponible, base, cuota, exenciones, bonificaciones, recaudación, apremio..., y en el segundo se establecerían determinadas singularidades respecto de las relaciones jurídico privadas de carácter ordinario.

\section{BIBLIOGRAFÍA}

COLOMER FERRÁNDIZ, JOSÉ V. “Centros Integrados de M ercancías".Fundación Instituto Valenciano de Estudios del Transporte.(1995).

ENTE PÚBLICO PUERTOS DEL ESTADO "Guía para el desarrollo de Zonas de Actividades L ogísticas Portuarias". (2002). 
GALÁN VIOQUE, ROBERTO. "O bras públicas de interés gen eral" Sevilla : Instituto Andaluz de Administración Pública, 2004.

GARAYAR JAVIER, EMILIANO "Con trol de concentraciones empresariales". Dykinson 2005.

GONZÁLEZ ROMERO, GEMA. “Innovación, redes y territorio en Andalucía".Universidad de Sevilla. Consejería de Obras Públicas y Transportes.

LÓ PEZ LÓ PEZ, MIGUEL ÁNGEL, “L os puertos secos: un inten to decaracterización jurídica". Revista del Derecho de las Telecomunicaciones e I nfraestructuras en Red - Núm. 4, Marzo 1999.

LÓPEZ RUEDA, FRANCISCO CARLOS, "EI régimen jurídico de la carga y descarga en el transporte de mercancías".Servicio Central de publicaciones del Gobierno Vasco.(2005).

RODIÈRE, R.y DU PONTAVICE, E., “Droit M aritime” 11.a ed., Dalloz, París, 1991.

RODRIGO DE LARRUCEA, J., "L a multimodalidad como concepto innovador del transporte (I parte)". Boletín del Instituto Europeo de Estudios Marítimos N ewsletter, 1992. 